\title{
Vitamin D Supplementation Rescues Aberrant NF- $\kappa$ B Pathway Activation and Partially Ameliorates Rett Syndrome Phenotypes in Mecp2 Mutant Mice
}

\author{
Mayara C. Ribeiro, ${ }^{1}$ Seth M. Moore, ${ }^{1}$ Noriyuki Kishi, ${ }^{2}$ 'Jeffrey D. Macklis, ${ }^{2, *}$ and ${ }^{-}$Jessica L. MacDonald ${ }^{1,2, *}$
}

https://doi.org/10.1523/ENEURO.0167-20.2020

${ }^{1}$ Department of Biology, Program in Neuroscience, Syracuse University, Syracuse, NY 13244 and ${ }^{2}$ Department of Stem Cell and Regenerative Biology, and Center for Brain Science, Harvard University, Cambridge, MA 02138

\begin{abstract}
Rett syndrome $(R T T)$ is a severe, progressive X-linked neurodevelopmental disorder caused by mutations in the transcriptional regulator MECP2. We previously identified aberrant $\mathrm{NF}-\kappa \mathrm{B}$ pathway upregulation in brains of Mecp2-null mice and demonstrated that genetically attenuating NF- $\kappa$ B rescues some characteristic neuronal RTT phenotypes. These results raised the intriguing question of whether NF- $\kappa$ B pathway inhibitors might provide a therapeutic avenue in RTT. Here, we investigate whether the known NF- $\kappa$ B pathway inhibitor vitamin $\mathrm{D}$ ameliorates neuronal phenotypes in Mecp2-mutant mice. Vitamin D deficiency is prevalent among RTT patients, and we find that Mecp2-null mice similarly have significantly reduced 25(OH)D serum levels compared with wild-type littermates. We identify that vitamin $\mathrm{D}$ rescues aberrant NF- $\kappa \mathrm{B}$ pathway activation and reduced neurite outgrowth of Mecp2 knock-down cortical neurons in vitro. Further, dietary supplementation with vitamin D in early symptomatic male Mecp2 hemizygous null and female Mecp2 heterozygous mice ameliorates reduced neocortical dendritic morphology and soma size phenotypes and modestly improves reduced lifespan of Mecp2-nulls. These results elucidate fundamental neurobiology of RTT and provide foundation that NF- $\kappa \mathrm{B}$ pathway inhibition might be a therapeutic target for RTT.
\end{abstract}

Key words: epigenetics; neocortex; neuronal morphology; NF- $\kappa$ B; Rett syndrome; vitamin D

\section{Significance Statement}

There is currently no effective treatment for Rett syndrome (RTT); however, selectively re-expressing Mecp2 in adult mice has shown that RTT symptoms can be partially reversed, suggesting that restoration of homeostasis of downstream targets of MeCP2 could also reverse or alleviate RTT symptoms. One such potential target is the NF- $\kappa \mathrm{B}$ pathway, which is aberrantly upregulated in the brain of Mecp2-mutant mice. Genetically reducing NF- $\kappa$ B signaling in these mice improves neuronal phenotypes. Here, we identify that the known NF- $\kappa \mathrm{B}$ inhibitor vitamin D reduces the aberrant NF- $\kappa \mathrm{B}$ signaling in Mecp2 knock-down neurons and partially ameliorates neuronal size and complexity phenotypes in both male and female Mecp2-mutant mice. Thus, this simple, cost-effective dietary supplement could contribute toward a partial therapeutic avenue in RTT.

\section{Introduction}

There is currently no effective treatment for Rett syndrome (RTT), a severe X-linked progressive neurodevelopmental disorder caused by mutations in the

Received April 29, 2020; accepted April 30, 2020; First published May 11, 2020.

The authors declare no competing financial interests. transcriptional regulator MECP2 (Amir et al., 1999). Girls with this devastating disorder develop relatively normally for 6-18 months, after which they undergo a period of rapid regression, with loss of motor skills, including

Author contributions: M.C.R., S.M.M., N.K., J.D.M., and J.L.M. designed research; M.C.R., S.M.M., and J.L.M. performed research; M.C.R. and J.L.M. analyzed data; M.C.R., J.D.M., and J.L.M. wrote the paper. 
purposeful hand movement, deceleration of head growth, and onset of repetitive, autistic behaviors (Chahrour and Zoghbi, 2007). Importantly, selectively re-expressing Mecp2 in adult mice has shown that RTT symptoms can be partially reversed (Luikenhuis et al., 2004; Giacometti et al., 2007; Guy et al., 2007), indicating that MeCP2 is necessary for both the development and maintenance of mature neurons (McGraw et al., 2011; Nguyen et al., 2012). These results suggest the potential for postsymptomatic therapeutic intervention, and open up the exciting prospect to at least partially stall or reverse phenotypic progression by restoring homeostasis of downstream targets of MeCP2.

One such potential downstream target is the NF- $\kappa \mathrm{B}$ pathway. The NF- $\kappa \mathrm{B}$ pathway regulates many cellular processes, including neural process development, structural plasticity, and learning and memory (Gutierrez and Davies, 2011). Mutations in components of the NF- $\kappa$ B pathway cause a spectrum of cognitive phenotypes in humans, including intellectual disability and autism spectrum disorders (ASDs; Mochida et al., 2009; Philippe et al., 2009; Manzini et al., 2014). Previously, we identified aberrant upregulation of Irak1, encoding a signaling kinase and scaffold protein within the NF- $\kappa$ B pathway, in purified cortical callosal projection neurons (CPNs) from male Mecp2-null mice (Kishi et al., 2016). Upregulation of Irak1 has also been observed in different regions of the brain across RTT mouse models, correlating with phenotype severity (Gabel et al., 2015), further supporting our results. We found that Irak1 overexpression recapitulates the reduced dendritic complexity phenotype of Mecp2null CPN, and that NF- $\kappa$ B pathway signaling is aberrantly upregulated in cortical neurons with Mecp2 loss-of-function. We genetically attenuated the aberrant NF- $\kappa$ B signaling in Mecp2-null mice by crossing them with mice heterozygous for Nfkb1. Strikingly, this genetic attenuation partially rescues the reduced cortical dendritic complexity in Mecp2-null mice, a hallmark of RTT that is recapitulated in these animals, and it substantially extends their normally shortened lifespan.

This work is based on preliminary data obtained with seed funding from the Rett Syndrome Research Trust (J.D.M.) and was partially supported by the National Institutes of Health (NIH) Director's Pioneer Award DP1 NS106665 (to J.D.M.), the Emily and Robert Pearlstein Fund (J.D.M.), and the Max and Anne Wien Professorship (J.D.M.). This work was also supported by the NIH/ National Institute of Neurological Disorders and Stroke Grant 1R01NS106285 (to J.L.M.), the International Rett Syndrome Foundation Grant 3604 (to J.L.M.), and the Syracuse University Collaboration for Unprecedented Success and Excellence Grant Program (J.L.M.).

N. Kishi's present address: Laboratory for Marmoset Neural Architecture, RIKEN Center for Brain Science, Saitama 351-0198, Japan.

*J.D.M. and J.L.M. are co-senior authors.

Acknowledgements: We thank Ben Noble, Chloe Greppi, Gila Fridkis, Jaclyn Jakubowski, and Lorelle Parker for technical assistance and blinded analyses of neuronal morphology.

Correspondence should be addressed to Jessica L. MacDonald at jemacdon@ syr.edu or Jeffrey D. Macklis at jeffrey_macklis@harvard.edu.

https://doi.org/10.1523/ENEURO.0167-20.2020 Copyright $@ 2020$ Ribeiro et al.

This is an open-access article distributed under the terms of the Creative Commons Attribution 4.0 International license, which permits unrestricted use, distribution and reproduction in any medium provided that the original work is properly attributed.
There are many known inhibitors of the NF- $\kappa$ B pathway. The known ability of vitamin D to inhibit NF- $\kappa$ B signaling (Chen et al., 2013b; Lundqvist et al., 2014) is particularly compelling given the high prevalence of vitamin $\mathrm{D}$ deficiency in RTT patients (Motil et al., 2011; Sarajlija et al., 2013). Developmental vitamin D deficiency leads to severe neurodevelopmental disruptions and behavioral abnormalities in rodents (Eyles et al., 2013; Cui et al., 2017), and there is growing evidence of a correlation between vitamin $D$ deficiency and neurodevelopmental disorders, including ASD (Cannell, 2013; Patrick and Ames, 2014; Fernell et al., 2015), epilepsy (Hollo et al., 2014), and cognitive function (Mayne and Burne, 2019). Vitamin D supplements can improve behavioral measures in some children with ASD (Jia et al., 2015) and phenotypes in rodent models of ASD-like characteristics (Du et al., 2017; Vuillermot et al., 2017). The precise mechanisms by which vitamin $\mathrm{D}$ regulates neurodevelopment are not known, and might include modulation of NF- $\kappa \mathrm{B}$ as well as parallel pathways.

Here, we investigated whether vitamin $D$ supplementation can inhibit the aberrant NF- $\kappa$ B signaling in cortical neurons that occurs with Mecp2 loss-of-function and whether such supplementation can ameliorate RTT phenotypes in male and female Mecp2 mutant mice. We determined that addition of the activated form of vitamin $D$ rescues the increased NF- $\kappa \mathrm{B}$-dependent transcription that occurs with Mecp2 knock-down and increases neurite outgrowth in vitro. Further, we employed custom chow to discover that dietary vitamin $\mathrm{D}$ supplementation in vivo rescues the neuronal morphology of both male Mecp2-null and female heterozygous mice, and modestly extends the lifespan of male Mecp2-nulls. These results provide proof-of-concept that NF- $\kappa$ B pathway inhibition, including via vitamin $\mathrm{D}$ supplementation, could provide a novel therapeutic target for some RTT phenotypes.

\section{Materials and Methods}

\section{Experimental design and statistical analyses}

Animals were placed on custom chow in a rotating order based on date of birth. In rare instances when a litter contained three or more nulls or heterozygous females, the mice were randomly divided into two cages by an investigator blinded to experimental conditions, and were treated as sequential litters to avoid over-representation of littermates in one treatment group. Mice were weighed weekly, and assessed with a phenotypic score following criteria established by Guy et al. (2007) by an investigator blinded to genotype and chow concentration. In brief, the mice were evaluated for abnormal gait, hindlimb clasping, irregular breathing, tremor, impaired mobility and poor general body condition. Each symptom was scored as 0 (absent), 1 (present), or 2 (severe), and the score for each symptom was summed to provide an overall phenotype score with a maximum possible score of 12 . Any mouse scoring a 2 (highly symptomatic) for general body condition, tremor, or breathing, or that lost $>20 \%$ of presymptomatic body weight was euthanized, and the day of euthanasia was considered day of death for lifespan analysis. The selection of sample size was based on standards 
in the field, and on criteria established by the RTT research community (Katz et al., 2012). All morphologic and phenotypic analyses were performed by investigators blinded to experimental conditions (genotype and treatment group).

GraphPad Prism 8.0 (GraphPad Software) was used to carry out the statistical analyses. No statistical methods were used to predetermine sample sizes, but our sample sizes are similar to those generally employed in the field. Our statistical tests consisted of two-tailed $t$ test, oneway ANOVA with Tukey's multiple comparison, or twoway ANOVA with Bonferroni post hoc test analyses to determine statistical significance between groups. Data distribution was handled as if normal, but this was not formally tested (since potential differences in results would be minor). Variance between groups was analyzed using the $f$ test procedure. For the survival curve analysis, we used the log-rank test, since this method is commonly used to compare the survival distributions of two groups. All data shown represent mean \pm SEM. Sample size and statistical test are specified in each figure legends.

\section{Animals}

All animal experimental protocols were approved by the Harvard University and/or Syracuse University Institutional Animal Care and Use Committee and adhere to NIH guidelines. Mice were group housed at a maximum of five mice per cage on a 12/12 $\mathrm{h}$ light/dark cycle and were given food and water ad libitum. CD-1 timed pregnant female mice were purchased from Charles River. Female Mecp2 heterozygous mice were purchased from The Jackson Laboratory (B6.129P2(C)-

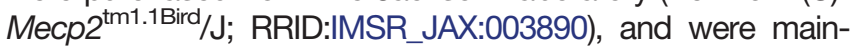
tained on a C57BL/6 background. Genotypes were determined by PCR on genomic DNA as follows: Mecp2 mutant mice, forward primer olMR1436 5' - GGT AAA GAC CCA TGT GAC CC -3'; reverse primer olMR1437 5' - TCC ACC TAG CCT GCC TGT AC -3'; reverse primer olMR1438 5'- GGC TTG CCA CAT GAC AA-3'.

\section{Constructs}

To knock down Mecp2 expression, a construct consisting of a bicistronic cassette encoding an shRNA sequence targeted against Mecp2 driven by a U6 promoter, and GFP driven by a ubiquitin promoter, was used. In control experiments, a scrambled sequence replaced the Mecp2 shRNA (both constructs were a generous gift of $Z$. Zhou, University of Pennsylvania; Zhou et al., 2006). To measure NF- $\kappa$ B activation, a plasmid containing 5 copies of an NF- $\kappa$ B response element (NF- $\kappa \mathrm{B}-\mathrm{RE}$ ) driving expression of the luciferase reporter gene luc2P was purchased from Promega (catalog \#E8491). Relative luminescence was normalized to a cotransfected Renilla luciferase construct, derived from the psiCHECK-2 vector (Promega, catalog \#C8021) with the HSV-TK promoter and Firefly luciferase cut out by digestion with Notl and Xbal.

\section{Embryonic cortical neuron culture}

Embryonic day (E)15.5 embryos were collected from timed pregnant CD-1 mice and the cortex was dissected out in dissociation medium (DM) containing MgKyn (Sigma-
Aldrich), glucose, AP-V (Sigma-Aldrich), penicillin-streptomycin (Invitrogen), and B27 supplement (Invitrogen). The cells were dissociated using cysteine (Sigma-Aldrich), papain, and OptiMem media. Glass coverslips were precoated with poly-D-lysine hydrobromide (Sigma-Aldrich P-6407). For neurite outgrowth experiments, 5 million cells were electroporated with $20 \mu \mathrm{g}$ of either shScram or shMecp2 plasmid (BTX ECM 830 Square Wave Electroporation system, following the parameters: $700 \mathrm{~V}$, one unipolar pulse at 100$\mu$ s pulse length in a 100-ms interval). After a recovery period of $5 \mathrm{~min}, 50,000$ cells per coverslip were plated in neurobasal based medium containing Glutamax (Invitrogen), fetal bovine serum (Invitrogen), and penicillin-streptomycin (Invitrogen). After $4 \mathrm{~h}$, the plating medium was removed, and growth medium was added, which contained Neurobasal (Invitrogen), Glutamax (Invitrogen), penicillin-streptomycin (Invitrogen), N2 and B27 supplements (Invitrogen). Calcitriol treatment started on day in vitro (DIV)2 and continued until the cells were fixed on DIV7. For p65 nuclear quantification experiments, 50,000 cells were plated per coverslip immersed in plating medium for $4 \mathrm{~h}$ before being replaced by growth media. On DIV3, cells were transfected via lipofectamine 2000 (Invitrogen) with $1 \mu \mathrm{g} / \mu \mathrm{l}$ of either shScram or shMecp2 plasmid, following manufacturer guidelines. Calcitriol treatment started on DIV4 and lasted until the cells were fixed on DIV14; $10 \mu \mathrm{M}$ calcitriol stock solution was prepared by dissolving 1 $\alpha, 25$-dihydroxyvitamin $\mathrm{D}_{3}$ (SigmaAldrich) in ethanol. For the no treatment group, only growth medium was added; for the vehicle group, only ethanol was added; for the treatment group, $100 \mathrm{~nm}$ of calcitriol stock solution was added. The final ethanol concentration for both the vehicle and calcitriol groups was $1 \%$. Growth medium was changed every other day.

\section{Immunocytochemistry}

Coverslips containing DIV7 or DIV14 cells were fixed with 4\% paraformaldehyde in PBS for 15 min, followed by three PBS washes. The cells were blocked with $8 \%$ goat serum, $10 \%$ Triton X-100, and 0.3\% bovine serum albumin (SigmaAldrich) in PBS for $20 \mathrm{~min}$. The coverslips were then incubated in primary antibodies diluted in blocking solution for $1 \mathrm{~h}$. Coverslips were rinsed three times with PBS for $5 \mathrm{~min}$ each and incubated in secondary antibodies diluted in blocking solution for $1 \mathrm{~h}$. The coverslips were washed three times with PBS, rinsed with $1 / 3 \mathrm{~PB}$, and mounted on a slide in Fluoromount (SouthernBiotech) before imaging. Antibody dilutions were as follows: rabbit $\alpha$-MeCP2 (1:500, Cell Signaling Technology catalog \#3456, RRID:AB_2143849), chicken $\alpha$-GFP IgY (1:1000, Thermo Fisher Scientific catalog \#A10262, RRID:AB_2534023), rabbit $\alpha$-NF- $\kappa$ B P65 (1:500, Cell Signaling Technology catalog \#8242, RRID:AB 10859369), and mouse $\alpha$-MAP2 (1:1000, Sigma-Aldrich catalog \#M1406, RRID:AB_477171). Secondary antibodies from Invitrogen Alexa Series were used based on the primary antibody dilution (1:500 or 1:1000, Invitrogen).

\section{p65 nuclear quantification}

Cortical neurons positive for both GFP and MAP2 were imaged with a Nikon Ni-U upright fluorescence 
microscope with a Zyla CMOS digital camera. Three independent experiments were performed, and 6-10 neurons per condition were imaged from each experiment. DAPI was used to identify the nucleus, and p65 translocation was quantified using ImageJ as corrected total cell fluorescence [CTCF $=$ integrated density - (area of selected cell $\times$ mean fluorescence of background readings)] (Burgess et al., 2010; McCloy et al., 2014). Images were assembled using Photoshop CC 2017 (Adobe).

\section{NF- $\kappa$ B luciferase reporter assays}

Postnatal day (P)1 C57BL/6 wild-type brains were dissected and dissociated as described for embryonic cultures. Dissociated cells were nucleofected with the $\mathrm{NF}-\kappa \mathrm{B}$ reporter construct and control Renilla luciferase construct, along with either scrambled shRNA or Mecp2 shRNA constructs, using an Amaxa Mouse Neuron Nucleofector kit (Lonza) and the Amaxa Nucleofector II Device (Lonza). Cells were cultured for $48 \mathrm{~h}$ at high density in 96-well plates coated with poly-D-lysine (SigmaAldrich), in growth medium composed of $50 \%$ DMEMF12 and 50\% Neurobasal (Invitrogen), with N2, B27, and GlutaMax supplements (Invitrogen). Calcitriol or vehicle control was added at $24 \mathrm{~h}$. At $48 \mathrm{~h}$, Firefly and Renilla luciferase activities were measured using the DualGlo Luciferase Assay system (Promega) and a GloMax 96 microplate luminometer (Promega). The luminescence of each well was normalized individually, and triplicate wells were averaged within each experiment. Relative luminescence was normalized to the control, shScram experimental condition, and data represent four independent biological replicates.

\section{Quantitative real-time PCR (qPCR)}

RNA was extracted using TRIzol (Invitrogen), and cDNA was synthesized using iScript cDNA synthesis kit (BioRad Laboratories) or qScript cDNA SuperMix (Quanta Biosciences). qPCR was performed on a CFX Connect Real-Time System (Bio-Rad Laboratories) according to the manufacturer's instructions. Primer pairs for Mecp2, Irak1, Gapdh, and S16 were as follows; each primer of each primer pair was designed in different exons, so as not to amplify genomic DNA:

Irak1: forward 5'- GCTGTGGACACCGATACCTT -3'; reverse 5' - GGTCACTCCAGCCTCTTCAG -3';

Gapdh: forward 5'- GGCATTGCTCTCAATGACAA -3'; reverse 5' - TGTGAGGGAGATGCTCAGTG -3';

S16: forward 5'- CACTGCAAACGGGGAAATGG -3'; reverse 5' - TGAGATGGACTGTCGGATGG -3';

Mecp2: forward 5' - TATTTGATCAATCCCCAGGG -3'; reverse 5' - CTCCCTCTCCCAGTTACCGT -3'.

We used PerfeCTa SYBR Green FastMix (Quanta Biosciences) Master mix, and each PCR consisted of $1 \times$ LightCycler FastStart DNA Master SYBR Green I mixture, $0.2 \mu \mathrm{m}$ primers, and cDNA. We used the mean of Gapdh and $\$ 16$ expressions as the reference gene. Each sample was run in triplicate and averaged. The relative quantification analysis was performed as follow: $\Delta \mathrm{Cq}=\mathrm{Cq}$ of gene of interest - geometric mean of $\mathrm{Cq}$ of reference genes;
$\Delta \Delta \mathrm{Cq}=\Delta \mathrm{Cq}-$ mean of $\Delta \mathrm{Cq}$ of wild-type samples; fold change $=2^{-\Delta \Delta \mathrm{Cq}}$. We also performed melt curve analysis to verify the specificity of the amplicons.

\section{Vitamin D serum measurements}

Serum was collected from four pairs of Mecp2+/y and Mecp2-/y littermates at eight weeks of age, following standard protocols. Total serum 25(OH)D levels were measured by radioimmunoassay by Heartland Assays. For measurement of the vitamin $D$ supplemented animals, three to four serum samples of Mecp2+/y and Mecp2-/y littermates at eight weeks of age and three to four serum samples of Mecp2+/+ and Mecp2 +/- littermates at five months of age on the different concentrations of vitamin $D$ were analyzed via mass spectrometry by ZRT Laboratories.

\section{Vitamin D supplementation}

Custom chow obtained from Bio-Serv was based on the AIN-93G Rodent Diet, varying only in Vitamin $D_{3}$ concentration. Male Mecp2+/y and Mecp2-/y littermates, and female Mecp2+/+ and Mecp2+/- littermates were each weaned together at four weeks of age, and placed on chow containing $1 \mathrm{lU} / \mathrm{g}$ vitamin $\mathrm{D}$ (standard chow), $10 \mathrm{lU} / \mathrm{g}$, or $50 \mathrm{lU} / \mathrm{g}$ in rotating order based on date of birth. As per established standards for preclinical studies in Mecp2-null mice (Katz et al., 2012), 15-18 Mecp2-/y mice were analyzed for lifespan and phenotypic progression for each vitamin D concentration. Mice were weighed weekly, and assessed with a phenotypic score following criteria established by Guy et al. (2007), by an investigator blinded to genotype and chow concentration. Any mouse scoring a 2 (highly symptomatic) for general body condition, tremor, or breathing, or that lost $>20 \%$ of presymptomatic body weight, was euthanized, and the day of euthanasia was considered day of death for lifespan analysis.

\section{Golgi staining, dendrite and soma measurements}

For dendrite and soma size analyses, four to five mice of each sex and genotype were analyzed per condition, as per established standards. Mice were euthanized with avertin overdose (at eight weeks of age for males and five months of age for females), and brains were immersed in freshly prepared Golgi impregnation solution (FD Rapid GolgiStain kit; FD Neurosciences). Brains were processed according to the protocol provided by the company. Neurons were systematically selected for analysis, and imaged by an investigator blinded to genotype and experimental condition with the following a priori selection criteria: (1) overall cellular morphology of superficial layer cortical pyramidal neurons; (2) dendritic trees well impregnated, and not obscured by stain precipitate, blood vessels, or astrocytes; and (3) the entire dendritic tree appearing intact and visible within the 150- $\mu \mathrm{m}$ thickness of the section. Neurons were imaged on a Nikon Ni$\mathrm{U}$ upright microscope with a Zyla CMOS digital camera under a $20 \times$ objective, equipped with an Optiscan XYZ motorized stage to allow for Z-stacks. NIS-Elements 
software was used for simple deconvolution and extended depth of focus, after which the neurons were traced using Adobe Illustrator CS5 (Adobe). Dendritic complexity was quantified using Sholl analysis (Sholl, 1953), employing ImageJ (W. S. Rasband, ImageJ, National Institutes of Health) with the Sholl Analysis Plugin (v1.0; Ghosh Lab, www.ghoshlab.org/software/index. html). The following parameters were used for dendrite analysis: step $=10 \mu \mathrm{m}$, beginning radius $=20 \mu \mathrm{m}$, final radius $=200 \mu \mathrm{m}$.

\section{Dendritic spines measurements}

For apical dendritic spine density quantification, three Mecp2-/y and Mecp2+/- littermates were analyzed per condition. Neurons were selected and imaged by an investigator blinded to genotype and experimental condition, following the criteria: (1) morphology of superficial layer cortical pyramidal neurons; (2) well impregnated dendritic trees; and (3) the entire apical dendritic tree appearing intact. Neurons were imaged under a $60 \times$-oil objective using with a Nikon $\mathrm{Ni}-\mathrm{U}$ upright microscope with a Zyla CMOS digital camera, and Optiscan XYZ motorized stage, enabling Z-stacks. For the quantification, we used the software RECONSTRUCT following the directions described (Risher et al., 2014). Images were reconstructed using Photoshop CC 2017 (Adobe).

\section{Results}

Vitamin D serum levels are reduced in Mecp2-/y mice

The high prevalence of vitamin D deficiency in RTT patients (Motil et al., 2011; Sarajlija et al., 2013), and the known ability of vitamin $\mathrm{D}$ to inhibit the NF- $\kappa$ B pathway (Stio et al., 2007; Chen et al., 2013b; Lundqvist et al., 2014), which is upregulated in brains of hemizygous null (Mecp2-/y) male mice (Kishi et al., 2016), raises the intriguing questions of whether this simple, cost-effective dietary supplement might rescue the aberrant $\mathrm{NF}-\kappa \mathrm{B}$ pathway activation in these mice, and whether it can contribute to phenotypic improvement. To investigate this and to further test the mechanistic motivation for this approach, we first analyzed vitamin D levels in the serum of eight-week-old Mecp2-null mice and wild-type littermates $(M e c p 2+/ y)$ by radioimmunoassay. Previous studies employing dietary vitamin $\mathrm{D}$ supplementation in mice have demonstrated that $1,25(\mathrm{OH})_{2} \mathrm{D}_{3}$ levels in the brain corelate with plasma $25(\mathrm{OH}) \mathrm{D}_{3}$ levels (Spach and Hayes, $2005)$; thus, we measured plasma $25(\mathrm{OH}) \mathrm{D}_{3}$ levels. We found that, similar to RTT patients, Mecp2-null mice have significantly reduced $(\sim 50 \%)$ total serum $25(\mathrm{OH}) \mathrm{D}$ levels compared with wild-type littermates (Fig. 1A), further suggesting that vitamin $D$ supplementation might have therapeutic benefit.

\section{Vitamin D supplementation rescues aberrant NF- $\kappa$ B activation in cortical neurons in vitro}

Vitamin $D$ and its analogues have been found to inhibit the NF- $\kappa$ B pathway, but this has not been well-studied in neurons. In the inactive state, the $\mathrm{NF}-\kappa \mathrm{B}$ dimer is tethered in the cytoplasm by inhibitor of $\kappa \mathrm{B}\left(l_{\kappa} \mathrm{B}\right)$. When the pathway is activated, $I_{\kappa} \mathrm{B}$ is phosphorylated, targeting it for proteasomal degradation. The NF- $\kappa \mathrm{B}$ dimer is thus released, and translocates to the nucleus, where it binds to consensus NF- $\kappa$ B-REs in the DNA to activate transcription of target genes. The predominant form of NF- $\kappa \mathrm{B}$ in the nervous system is a p65/p50 heterodimer (Gutierrez and Davies, 2011), and NF- $\kappa \mathrm{B}$ subunits are expressed throughout the CNS, by neurons as well as by glia.

To investigate whether vitamin $D$ supplementation can rescue aberrant NF- $\kappa \mathrm{B}$ activation resulting from Mecp2 knock-down in cortical neurons, we first employed an in vitro NF- $\kappa \mathrm{B}-\mathrm{RE}$ luciferase assay. We previously employed this reporter construct with tandem $\mathrm{NF}-\kappa \mathrm{B}-\mathrm{RE}$ s and a minimal reporter driving luciferase to assay $\mathrm{NF}-\kappa \mathrm{B}$ transcriptional activity in cortical neurons following Irak1 overexpression or Mecp2 knock-down, and identified significant upregulation of NF- $\kappa \mathrm{B}$ dependent transcriptional activity (Kishi et al., 2016). We employed an shRNA-mediated Mecp2 knock-down approach in wild-type neurons, allowing for an efficient, higher-throughput in vitro system; the high transfection efficiency obtained with the nucleofection approach ( $\sim 60 \%$ of surviving cells) recapitulates the heterogeneous MeCP2 expression of a Mecp2+/- cortices. The Mecp2 knock-down and control shRNA constructs employed have been previously validated and published (Zhou et al., 2006; Wood et al., 2009; Kishi et al., 2016). Both constructs contain eGFP driven by an independent promoter. This shRNA-mediated knock-down of Mecp2 is sufficient to visibly reduce, but not eliminate, protein detection by immunocytochemistry in cortical neurons (Fig. $1 B, C$ ). In the vehicle control, Mecp2 knock-down results in an approximate 1.75-fold increase in NF- $\kappa$ B-dependent transcriptional activity relative to shScram, which is similar to the previously published $\sim 2$-fold increase observed with Mecp2 knock-down without treatment (Kishi et al., 2016). We treated neurons with the bioactive form of vitamin $D$ (1 $\alpha, 25$-dihydroxyvitamin $\mathrm{D}_{3}$; calcitriol) for $24 \mathrm{~h}$ before performing NF- $\kappa \mathrm{B}-\mathrm{RE}$ luciferase assays. We find that addition of calcitriol has no effect on relative NF- $\kappa$ B activation in control neurons but significantly reduces the elevated NF- $\kappa \mathrm{B}$ signaling in Mecp2 knock-down neurons, bringing the level back down to that of control neurons (Fig. 1D).

Next, we investigated whether calcitriol might also reduce nuclear translocation of the p65 subunit of NF- $\kappa \mathrm{B}$, which is indicative of $\mathrm{NF}-\kappa \mathrm{B}$ pathway activation. For these experiments, E15.5 cortical cells were dissociated and cultured for $14 \mathrm{~d}$. They were transfected with either shScram or shMecp2 at 3 DIV and treated with either vehicle (ethanol) or $100 \mathrm{~nm}$ calcitriol starting at 4 DIV. Transfected neurons were identified by co-expression of GFP and the neuronal marker MAP2. shMecp2-transfected neurons express higher levels of p65 protein in their nucleus compared with control (shScram)-transfected cells (Fig. 1E, left). Interestingly, the addition of the vehicle $(\mathrm{EtOH})$ increases p65 nuclear translocation in control transfected neurons, but not in Mecp2 knock-down neurons, perhaps indicating that pathway activation is 

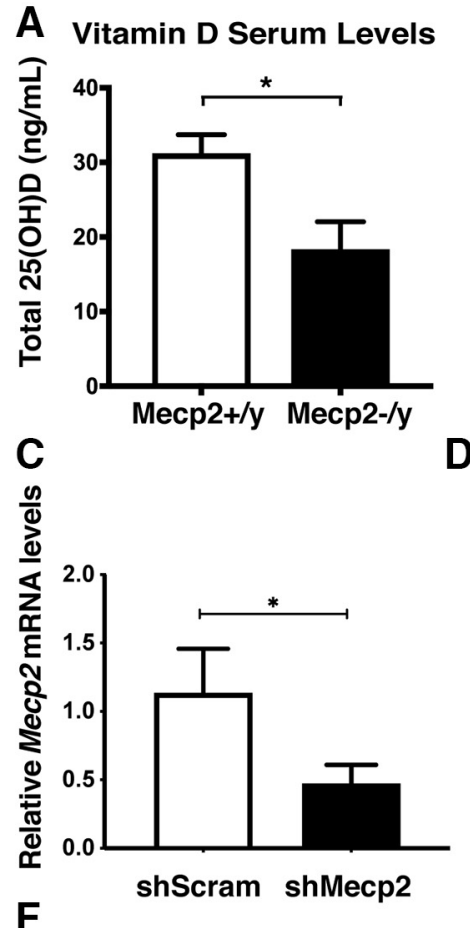

F
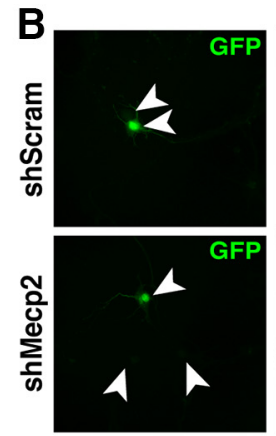

D

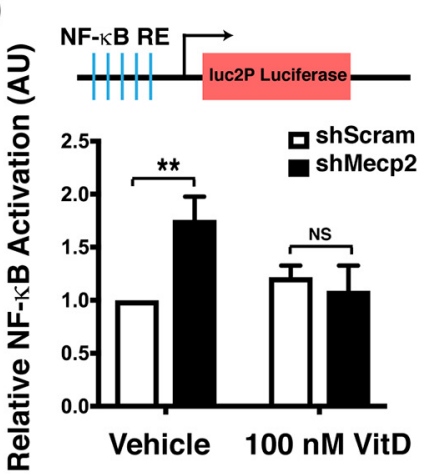

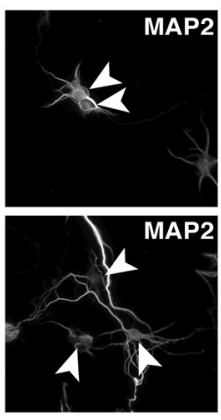
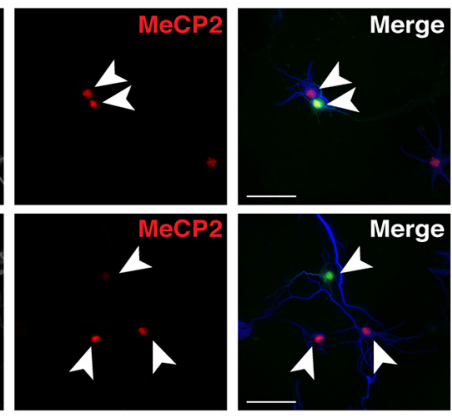

E

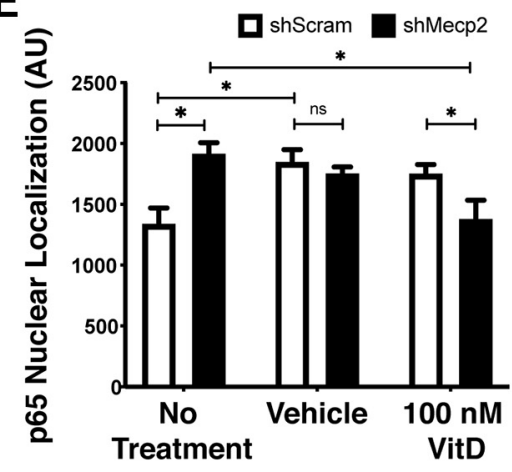

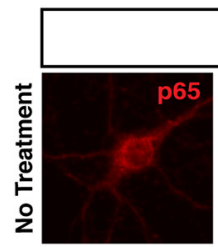
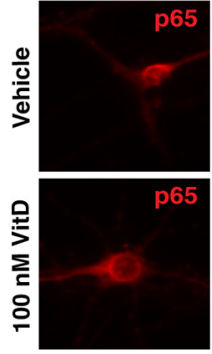
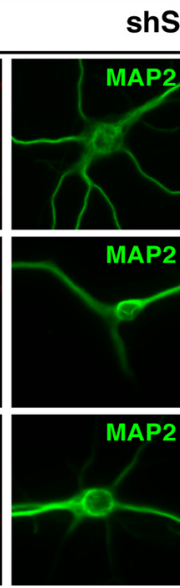

shScram

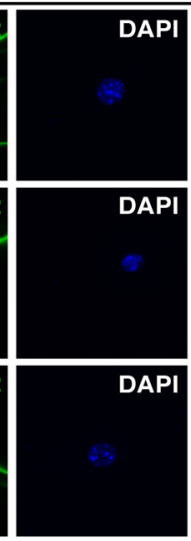

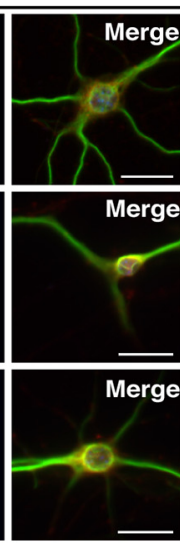
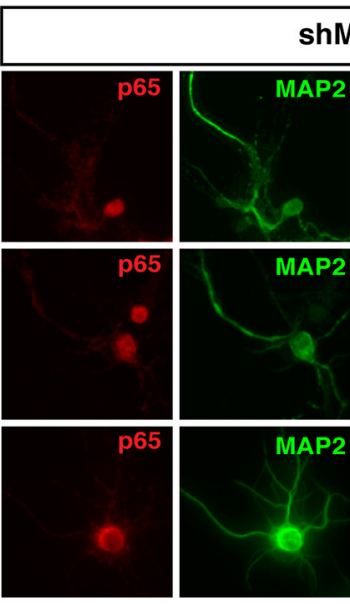

shMecp2

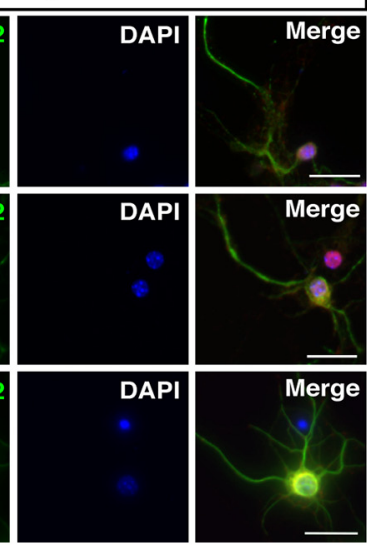

Figure 1. Vitamin D rescues aberrant NF- $\kappa$ B activation in Mecp2 knock-down cortical neurons. $\boldsymbol{A}$, Mecp2-null mice have reduced serum vitamin D levels $[25(\mathrm{OH}) \mathrm{D}]$ compared with the wild-type littermates at eight weeks of age $(N=4$ mice/genotype). B, C, E15.5 cortical neurons were nucleofected with a construct expressing GFP as reporter and either a control shRNA (shScram) or an shRNA targeting Mecp2 (shMecp2). shMecp2 nucleofection visibly reduced the expression of MeCP2 protein at 7 DIV (B) and downregulated the overall expression of Mecp2 $\sim 50 \%$ after 14 DIV, in cultures in which the transfection efficiency was $\sim 60 \%$ (C). Arrowheads indicate nucleofected GFP-positive neurons; arrows indicate neighboring non-nucleofected GFP-negative neurons. $N=4$ experimental replicates. $\boldsymbol{D}$, Dissociated P1 cortical neurons were nucleofected with shScram or shMecp2, then were cultured for $2 \mathrm{~d}$. Addition of calcitriol, the activated form of vitamin $\mathrm{D}$ (VitD), to culture medium for $24 \mathrm{~h}$ rescues the $\sim 1.75$-fold increase in $\mathrm{NF}-\kappa \mathrm{B}$-dependent transcription that occurs with knock-down of Mecp2 in cortical neurons in vitro. However, calcitriol has no effect on shScram control nucleofected neurons ( $N=4$ biological replicates). $\boldsymbol{E}, \boldsymbol{F}$, Mecp2 knock-down results in increased nuclear p65 localization in cortical neurons, which is indicative of NF- $\kappa \mathrm{B}$ activation. Addition of calcitriol to the culture medium reduces p65 protein expression in the nucleus of Mecp2 knock-down cortical neurons, but not control (shScram) neurons. $\boldsymbol{C}, \boldsymbol{D}, \boldsymbol{N}=\operatorname{shScram}$ no treatment: 33 neurons, vehicle: 30 neurons; 100 nм VitD: 33 neurons; shMecp2 no treatment: 23 neurons, vehicle: 22 neurons; 100 nм VitD: 22 neurons from three independent experiments. Expression of GFP was employed to identify transfected neurons. AU = relative luminescence units. $\boldsymbol{A}, \boldsymbol{B}, \boldsymbol{D}$, Two-tailed $t$ test. $\boldsymbol{E}$, One-way ANOVA with Tukey's multiple comparison test; $* p<0.05$, $* * p<0.01, \mathrm{NS}=$ not significant. Scale bar $=20 \mu \mathrm{m}$. Error bar: \pm SEM.

already maximal in these neurons (Fig. 1E, middle). Ethanol is known to alter NF- $\kappa$ B signaling via ROS-dependent pathways, increasing p65 phosphorylation and its nuclear translocation in neurons and glia (Davis and
Syapin, 2004; Lippai et al., 2013; Okabe et al., 2016; Vetreno and Crews, 2018). However, addition of $100 \mathrm{~nm}$ calcitriol reduces p65 nuclear localization in Mecp2 knock-down neurons without affecting the control 
neurons (Fig. 1E,F), indicating that vitamin $D$ supplementation can reduce aberrant NF- $\kappa \mathrm{B}$ signaling in Mecp2-deficient cortical neurons in vitro.

\section{Vitamin $D$ rescues reduced neurite outgrowth of Mecp2 knock-down cortical neurons in vitro}

We next investigated whether addition of calcitriol might also rescue the reduced neurite outgrowth of Mecp2 knock-down neurons in vitro. E15.5 cortical neurons transfected with shMecp2 demonstrate a significant reduction in total neurite outgrowth by $7 \mathrm{DIV}$, in comparison to control shScram transfected neurons (Fig. $2 A-C$ ). Transfected neurons were again identified by GFP and MAP2 expression, with GFP used to trace total neurites. Calcitriol or ethanol (vehicle) was added to the culture medium from 2 to 7 DIV (Fig. $2 A, B$ ). The vehicle marginally reduced the total neurite outgrowth of both shScram and shMecp2 neurons; however, Mecp2 knock-down neurons have significantly decreased neurite length compared with shScram control, both in untreated and vehicletreated cultures. Ethanol has also been shown to negatively alter neuronal dendritic complexity and neurite development, as discussed above for p65 localization. However, there is no difference in total neurite outgrowth between vehicle and calcitriol treated shScram neurons, while there is a significant increase in total neurite outgrowth of shMecp2 neurons treated with calcitriol compared with vehicle. (Fig. 2C). Together, these data indicate that vitamin $D$ is able to act on neurons to modify $\mathrm{NF}-\kappa \mathrm{B}$ signaling and Mecp2 knock-down cortical neuronal phenotypes in vitro, thus motivating investigation of how vitamin D modifies Mecp2-mutant neuronal phenotypes in vivo.

\section{Dietary vitamin $\mathrm{D}$ supplementation moderately extends the reduced lifespan of Mecp2-null mice}

To investigate whether vitamin D supplementation might also improve specific Mecp2-null phenotypes in vivo, we treated Mecp2-null (Mecp2 ${ }^{\text {tm1.1Bird}}$ ) and wildtype littermates with vitamin $D$ supplemented chow and analyzed complexity and soma size of cortical neurons in one cohort of mice and overall phenotypic progression and (morbidity-limited) lifespan in a second cohort (Fig. $3 A)$. Mecp2-null and wild-type littermates were placed on chow containing one of three vitamin $\mathrm{D}$ concentrations in a strict rotation based on date of birth: $1 \mathrm{IU} / \mathrm{g}$ (standard chow concentration, serving as control), $10 \mathrm{IU} / \mathrm{g}$, or $50 \mathrm{lU} /$ $g$ vitamin D. Chow with $10 \mathrm{lU} / \mathrm{g}$ and $50 \mathrm{IU} / \mathrm{g}$ are well tolerated and can alter neuronal pathology (Gianforcaro and Hamadeh, 2012; Gianforcaro et al., 2013; Latimer et al., 2014). A pilot study included chow with $200 \mathrm{IU} / \mathrm{g}$ vitamin $\mathrm{D}$, which is well below the published toxic range; however, we found that it led to reduced lifespan in Mecp2-/y mice, and thus, this dosage was halted. Mice on a diet supplemented with $50 \mathrm{lU} / \mathrm{g}$ of vitamin D have more than a twofold increase in total 25(OH)D serum concentration compared with the mice on $10 \mathrm{lU} / \mathrm{g}$ of vitamin $\mathrm{D}$, regardless of genotype (Fig. 3B), indicating that the dietary supplementation is effective at increasing circulating vitamin

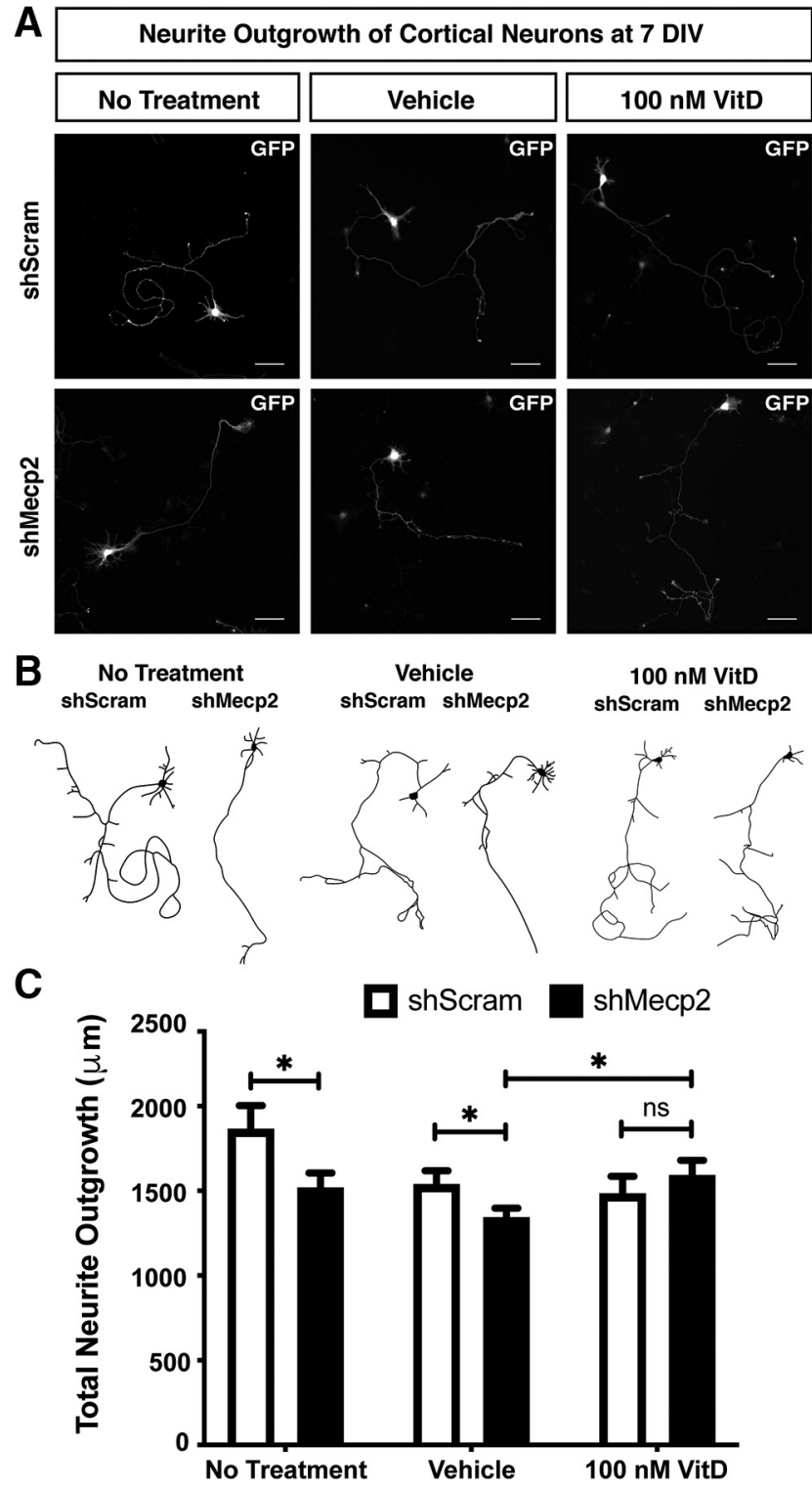

Figure 2. Vitamin $D$ rescues reduced neurite outgrowth of Mecp2 knock-down cortical neurons. A-C Dissociated E15.5 cortical neurons were nucleofected with a construct expressing a GFP reporter and either a control shRNA (shScram) or an shRNA targeting Mecp2 (shMecp2), then were plated and cultured for $7 \mathrm{~d}$. Neurons were either maintained in standard culture medium, or were supplemented with vehicle $(\mathrm{EtOH})$ or 100 nM calcitriol (VitD) from 2 to 7 DIV. $\boldsymbol{A}$, Representative images of GFP + cortical neurons at 7 DIV under each condition. $\boldsymbol{B}$, Representative traces of GFP + cortical neurons under each condition. C, Total neurite outgrowth of GFP + neurons was quantified from randomly selected neurons, from each of three independent experiments ( $N=$ shScram no treatment: 30 neurons, vehicle: 26 neurons; 100 nM VitD: 27 neurons; shMecp2 no treatment: 28 neurons, vehicle: 26 neurons; 100 nм VitD: 27 neurons). Supplementation with calcitriol rescues the reduced neurite outgrowth of Mecp2 knock-down neurons relative to $\mathrm{EtOH}$ vehicle control but does not have a significant effect on control cortical neurons. Thus, shMecp2 neurons with calcitriol are not significantly different from shScram. C, One-way ANOVA with Tukey's multiple comparison test; $* p<0.05$, NS = not significant. Scale bar $=50 \mu \mathrm{m}$. Error bar: \pm SEM. 
A

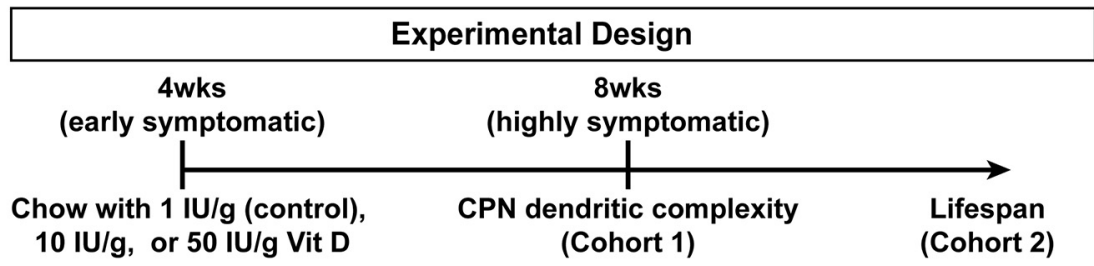

B

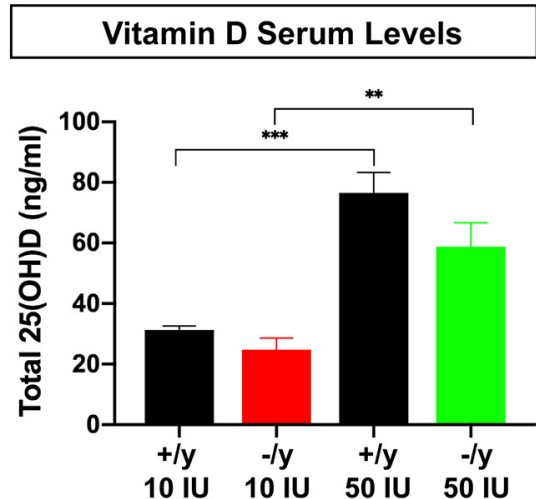

C Total Phenotypic Score

10 IU 10 IU 50 IU 50 IU
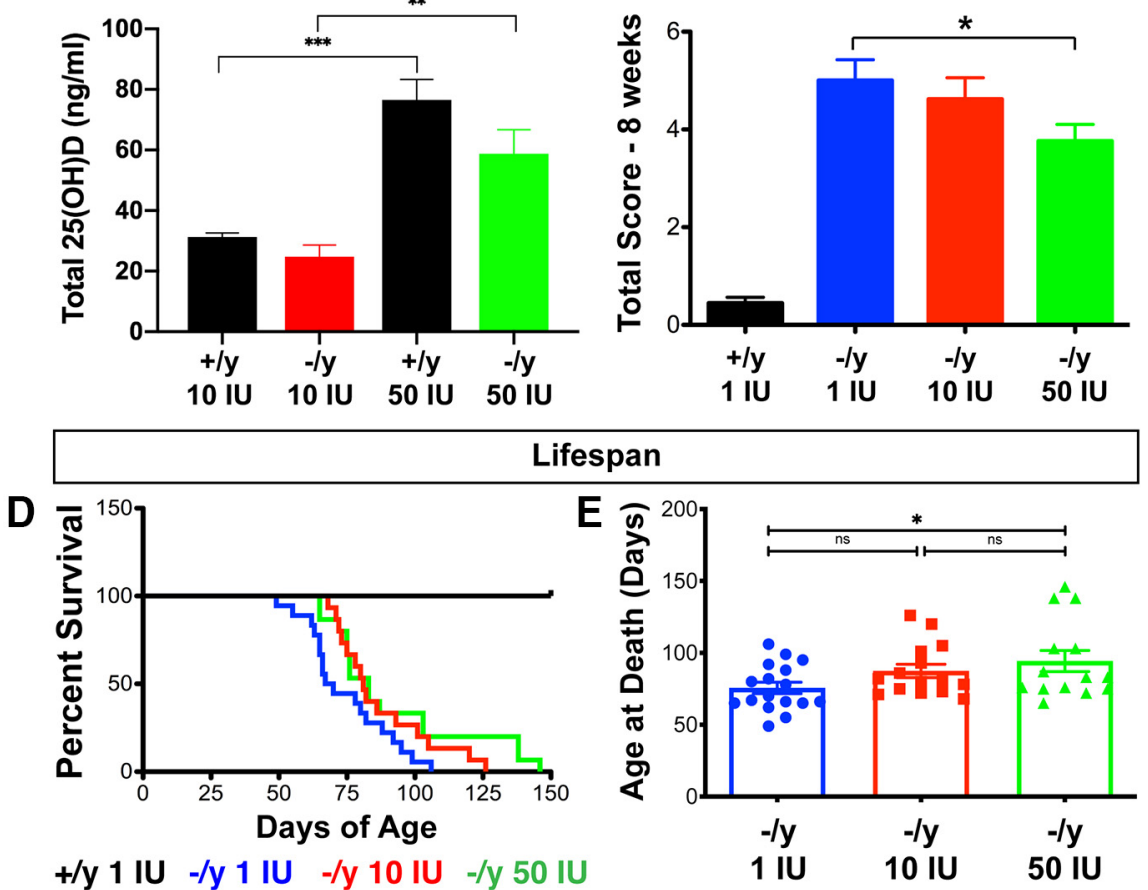

Figure 3. Vitamin D supplementation modestly improves Mecp2-null phenotypes and increases their reduced lifespan. $\boldsymbol{A}$, Experimental plan for in vivo vitamin D treatment of Mecp2-/y and Mecp2+/y littermates. B, Supplementing the diet of the mice with vitamin D (VitD) significantly increases their total serum levels of $25(\mathrm{OH}) \mathrm{D}$, regardless of genotype, which is most apparent with $50 \mathrm{IU} / \mathrm{g}$ supplemented chow. C, Mecp2-/y on $50 \mathrm{lU} / \mathrm{g}$ VitD have a small, but significant, reduction in total phenotypic score at eight weeks of age compared with Mecp2-/y on control $1 \mathrm{IU} / \mathrm{g}$ VitD. D, Kaplan-Meier survival curves. Mecp2-/y mice on $50 \mathrm{IU} / \mathrm{g}$ VitD chow survive significantly longer than Mecp2-/y mice on control chow, while Mecp2-/y mice on $10 \mathrm{IU} / \mathrm{g}$ VitD display a trend toward increased median lifespan $(p=0.04$; log-rank test). The median lifespan of $M e c p 2-/ y$ on $1 \mathrm{lU} / \mathrm{g}$ is $68.5 \mathrm{~d}, 81 \mathrm{~d}$ on $10 \mathrm{lU} / \mathrm{g}$, and $83 \mathrm{~d}$ on $50 \mathrm{IU} / \mathrm{g}$. E, The mean age of death of Mecp2-/y mice on the control chow is significantly lower than the animals on $50 \mathrm{lU} / \mathrm{g}$ VitD. B, C, E, One-way ANOVA with Tukey's multiple comparison test; $* p<0.05, * * p<0.01$, $* * * p<0.001$, NS = not significant. $\boldsymbol{B}, N=4$ mice per condition. $\boldsymbol{C}-\boldsymbol{E}, N=16 \mathrm{Mecp} 2+/ \mathrm{y} 1 \mathrm{IU}$, 17 Mecp2-/y 1 IU, 15 Mecp2-/y 10 IU, 14 Mecp2-/y 50 IU. Error bar: \pm SEM.

D in Mecp2-/y mice, beyond that observed in Mecp2+/y mice under control conditions (Fig. 1A).

At four weeks of age, Mecp2-/y mice are mildly symptomatic, already demonstrating reduced body weight relative to wild-type littermates, and a small, but significant increase in phenotypic score (data not shown). Dendritic complexity and soma size of Layer II/III CPN are not significantly disrupted in Mecp2-null mice at four weeks of age but are significantly reduced compared with wildtype by eight weeks of age (Kishi and Macklis, 2004). Mecp2-nulls display an overall rapid phenotypic progression between four and eight weeks of age and a median survival between 10 and 11 weeks (Guy et al., 2001); we thus treated the mice with vitamin $D$ during this critical window.
The mice were weighed weekly and assessed with a phenotypic score (Guy et al., 2007) by an investigator blinded to genotype and chow concentration. Briefly, the mice were assigned a score of 0 (absent), 1 (present), or 2 (severe) for each of the following six phenotypes: abnormal gait, hindlimb clasping, irregular breathing, tremor, impaired mobility, and poor general body condition. The score for each symptom was summed to provide an overall phenotype score, with a maximum possible score of 12.

While vitamin $\mathrm{D}$ supplementation does not significantly alter the reduced weight of Mecp2-/y mice, Mecp2-/y mice on $50 \mathrm{lU} / \mathrm{g}$ vitamin D demonstrate a small, but significant, reduction in total phenotypic score by eight weeks of age (Fig. $3 C$ ). Thus, to investigate whether vitamin $D$ 
supplementation can, indeed, slow broad phenotypic progression, we analyzed lifespan as an indicator of overall phenotypic progression and health. Following established standards for preclinical trials in Mecp2 mutant mice (Katz et al., 2012), 14-17 Mecp2-null mice and wild-type littermates were maintained on each vitamin $D$ concentration from four weeks of age until death.

Supplementation with $50 \mathrm{lU} / \mathrm{g}$ significantly increased the median lifespan of Mecp2-null mice (83 d, log-rank test $p=0.04$ ), while supplementation with $10 \mathrm{lU} / \mathrm{g}$ vitamin $\mathrm{D}$ produced a trend to increased median lifespan (from $68.5 \mathrm{~d}$ on control chow to $81 \mathrm{~d}$; Fig. $3 D$ ). The mean age at death is significantly increased for Mecp2-/y mice on $50 \mathrm{IU} / \mathrm{g}$ vitamin $\mathrm{D}$, relative to those on the control chow (Fig. $3 E$ ). While this $\sim 20 \%$ increase in survival is not as extensive as that obtained with genetic attenuation of NF$\kappa \mathrm{B}$ signaling (Kishi et al., 2016), it is similar to results seen with other treatments currently under investigation, such as human recombinant IGF1 (Castro et al., 2014). Taken together, these results provide highly intriguing evidence that dietary supplementation with vitamin D might provide a partial improvement of some RTT phenotypes.

\section{Dietary vitamin D supplementation rescues projection neuron dendritic complexity and soma size phenotypes in Mecp2-/y neocortex}

To investigate a specific RTT neuronal phenotype that is recapitulated in Mecp2 mutant mice, we analyzed the complexity and soma size of Layer II/III CPN. CPN, the broad population of commissural neurons whose axons connect the two cerebral hemispheres via the corpus callosum (CC), are excitatory pyramidal projection neurons whose cell bodies reside in neocortical Layers II/III ( $~ 80 \%$ in mouse), V ( 20\%), and a few \% in VI (Fame et al., 2011). Layer II/III CPN increasingly express MeCP2 as they mature, and loss of MeCP2 function reduces their dendritic complexity in a largely cell-autonomous manner (Kishi and Macklis, 2004, 2010). Reduced dendritic complexity of neocortical Layer II/ III CPN has also been observed in postmortem brains of RTT patients (Belichenko et al., 1994; Armstrong et al., 1995), with synaptic circuit abnormalities identified in this population in mouse (Wood et al., 2009). In fact, perturbed dendritic complexity of Layer II/III CPN is observed in multiple neurodevelopmental disorders, including ASD (Egaas et al., 1995; Piven et al., 1997; Mukaetova-Ladinska et al., 2004; Herbert and Kenet, 2007; Frazier and Hardan, 2009; Hardan et al., 2009; Srivastava et al., 2012), attention-deficit/hyperactivity disorder (Hynd et al., 1991; Roessner et al., 2004; Seidman et al., 2005), and schizophrenia (Swayze et al., 1990; Tibbo et al., 1998; Innocenti et al., 2003; Wolf et al., 2008). Further, genetic attenuation of the NF- $\kappa$ B pathway improves the reduced complexity of CPN in Mecp2-/y mice (Kishi et al., 2016). We thus focused on this important neuronal population as a window into the broader pathophysiology of RTT.

Supplementing with vitamin D between four and eight weeks of age has no significant effect on dendritic complexity or soma size of CPN in wild-type mice (Fig. $4 A-D$ ), nor does it affect overall health (measured by total phenotypic score) or weight of wild-type mice (Fig. 4E,F).
Thus, for clarity and rigor, we compare Mecp2-/y mice on all vitamin $\mathrm{D}$ concentrations to wild-type $(\mathrm{Mecp} 2+/ \mathrm{y})$ mice on $1 \mathrm{lU} / \mathrm{g}$ (control) chow in subsequent analyses. Strikingly, we find that supplementation with $50 \mathrm{lU} / \mathrm{g}$ vitamin $D$ fully rescues the reduced dendritic complexity of Mecp2-null Layer II/III CPN, as measured by Golgi staining and Sholl analysis (Fig. $5 A, B$ ). This rescue appears to result from both an increase in the number of branch points, relative to Mecp2-/y on control chow (Fig. 5C), and total dendritic length (Fig. 5D).

Further evaluation of the data reveals that the total dendritic length reduction in Mecp2-/y CPN is not due to primary dendrites, but, rather, to reduced secondary and tertiary + dendrites. Strikingly, these secondary and tertiary dendrites in Mecp2-/y mice receiving $50 \mathrm{lU} / \mathrm{g}$ of vitamin D supplementation are not significantly different from wild-type (Fig. 5E). However, this rescue is limited to basal dendrites; the total basal dendritic length of Mecp2-/y CPN on vitamin D supplementation is not significantly different from wild type, while the apical dendritic branches continue to show significant reduction in length (Fig. $5 F$ ). Further, $50 \mathrm{lU} / \mathrm{g}$ vitamin $\mathrm{D}$, but not $10 \mathrm{lU} /$ $\mathrm{g}$, rescues the reduced soma size of Mecp2-/y Layer II/III CPN (Fig. 5G). It is likely that the morphologic abnormalities observed in this neuronal population underlie at least some aspects of the cognitive, behavioral phenotypes observed in RTT, suggesting that amelioration of these phenotypes via vitamin $\mathrm{D}$ supplementation might potentially alleviate some RTT symptoms.

\section{Dietary vitamin D supplementation rescues dendritic spine density of Mecp2-/y CPN}

In addition to alterations in dendritic complexity and soma area of cortical neurons, RTT patients and Mecp2 mutant mice are known to have reduced dendritic spine density (Belichenko et al., 1994, 2009; Armstrong et al., 1995; Fukuda et al., 2005). To investigate whether vitamin D might rescue this phenotype, we analyzed apical dendrites of Layer II/III cortical projection neurons in the neocortex of eight-week-old Mecp2-null and wild-type mice on control (1 IU/g) and $50 \mathrm{IU} / \mathrm{g}$ vitamin D chow (Fig. 6A-D). We focused our analyses on $50 \mathrm{lU} / \mathrm{g}$ vitamin $D$ because this concentration rescues both dendritic complexity and soma size of the neurons. The data reveal significant reduction in spine density in the apical dendrites of Mecp2-/y mice on control chow, when compared with wild-type littermates. Vitamin D supplementation, however, fully rescues the decreased dendritic spine density of Mecp2-/y CPN, while not significantly altering the number of dendritic spines in wild-type littermates (Fig. $6 E)$. Together, these results indicate that dietary vitamin D supplementation is able to rescue reduced neuronal size and complexity of Mecp2-null neurons but does not modify morphology of wild-type neurons.

\section{Female Mecp2 heterozygous mice also display aberrant NF- $\kappa$ B pathway activation}

Although RTT is an X-linked disorder, and human males with a mutation in MECP2 rarely survive past birth, Mecp2 

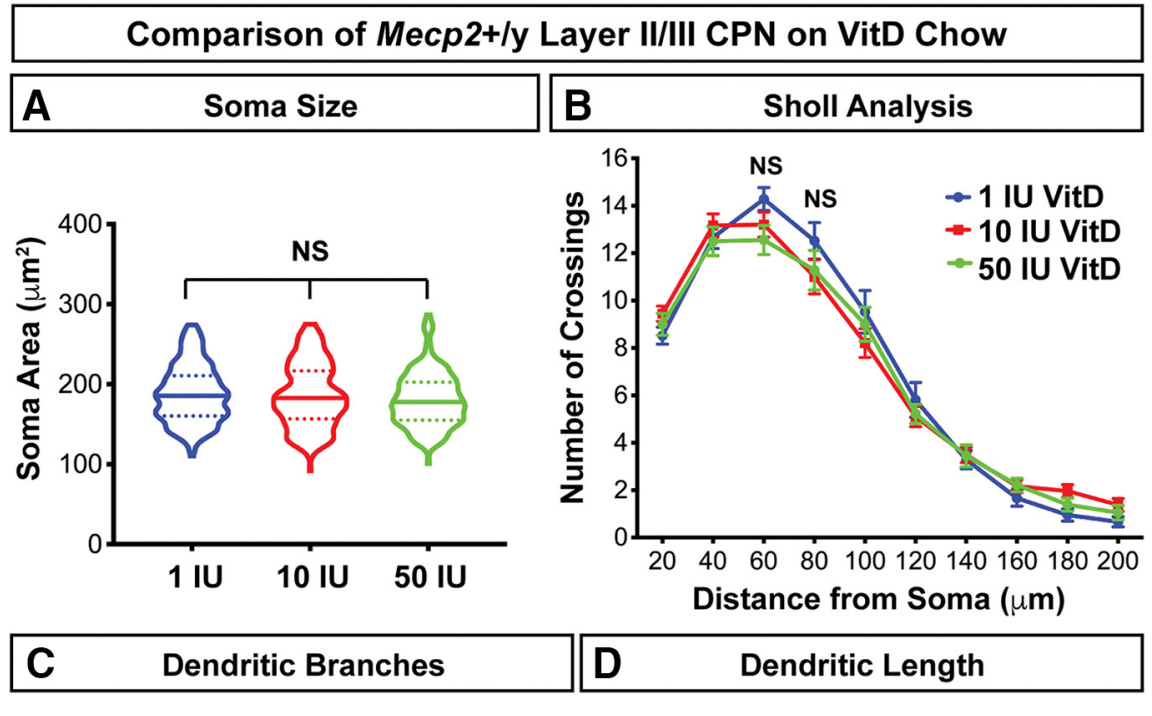

D Dendritic Length
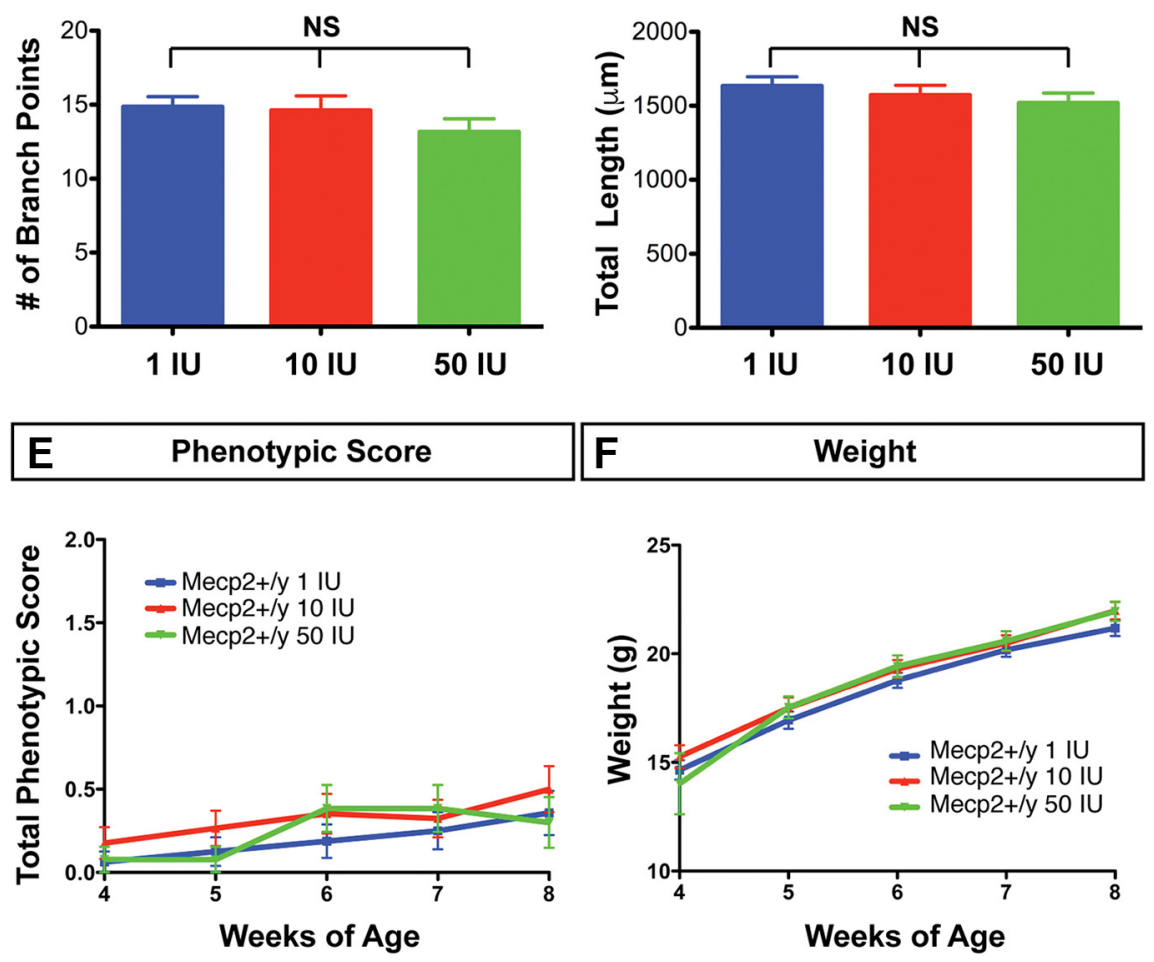

Figure 4. Dietary vitamin D supplementation does not significantly alter neuronal morphology or health in wild-type $(M e c p 2+/ y)$ mice. Treatment of $M e c p 2+/ y$ mice with vitamin D supplemented chow between four and eight weeks of age does not alter $(\boldsymbol{A})$ soma size $(p=0.67$, one-way ANOVA; $1 \mathrm{IU} / \mathrm{g} n=76,10 \mathrm{IU} / \mathrm{g} n=103,50 \mathrm{IU} / \mathrm{g} n=84)$ or $(\boldsymbol{B}-\boldsymbol{D})$ dendritic complexity of Layer II/III pyramidal neurons, as measured by Golgi staining and $(\boldsymbol{B})$ Sholl analysis, $(\boldsymbol{C})$ quantification of the number of dendritic branches, or $(\boldsymbol{D})$ quantification of total dendritic length ( $1 \mathrm{lU} / \mathrm{g} n=20$ neurons, $10 \mathrm{lU} / \mathrm{g} n=29,50 \mathrm{lU} / \mathrm{g} n=18$ ). In addition, vitamin D supplementation does not alter the $(\boldsymbol{E})$ total phenotypic score $(p=0.34$, one-way ANOVA) or $(\boldsymbol{F})$ weight of $M e c p 2+/ y$ mice $(p=0.66$, one-way ANOVA). B, $\boldsymbol{E}, \boldsymbol{F}$, Two-way ANOVA with Bonferroni post hoc tests. $\boldsymbol{A}, \boldsymbol{C}, \boldsymbol{D}$, One-way ANOVA with Tukey's post hoc tests. NS $=$ not significant. Error bar: \pm SEM.

loss-of-function is less severe in mice. Male hemizygous null mice not only survive until adulthood, they have been the most commonly studied model system. Heterozygous female mice (Mecp2+/-) have not been as thoroughly characterized, likely because of the added experimental challenges that they present, including delayed and more variable phenotypic progression, and cellular mosaicism due to X-inactivation (Guy et al., 2001; Samaco et al., 2013; Vogel Ciernia et al., 2017; Ribeiro and MacDonald, 2020). However, they are a more clinically relevant RTT model, and it has become a consensus opinion that it is imperative to include female Mecp2+/- for optimal information in studies of potential therapeutics (Katz et al., 2012). 


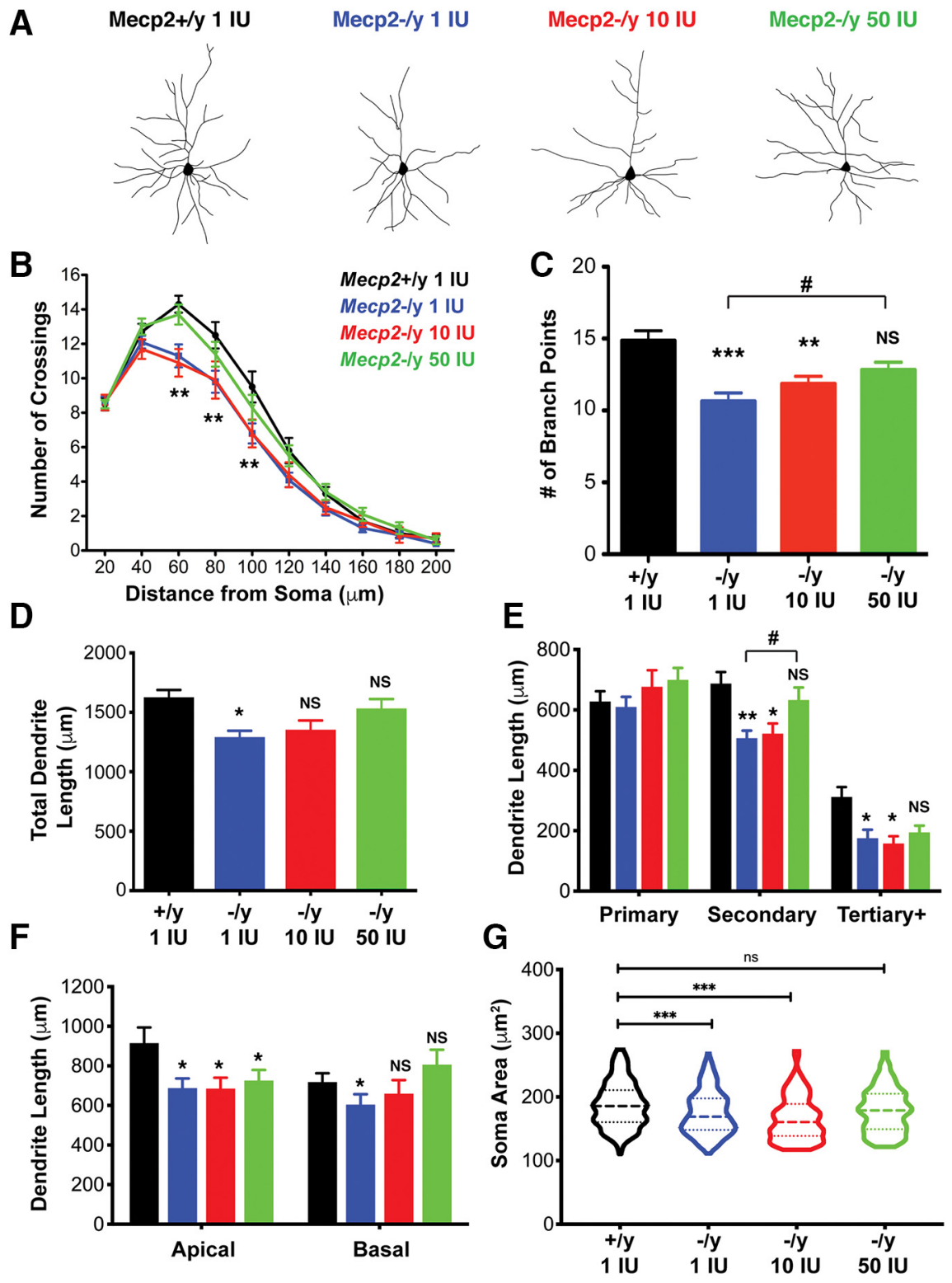

Figure 5. Vitamin D supplementation rescues reduced cortical dendritic complexity and soma size phenotypes in Mecp2-null mice. $\boldsymbol{A}$, Representative traces of Layer II/III cortical CPN following Golgi staining. $\boldsymbol{B}-\boldsymbol{F}$, Dendritic complexity of CPN, as measured by (B) Sholl analysis, $(\boldsymbol{C})$ number of branch points, and $(\boldsymbol{D})$ total dendritic length, is significantly reduced in Mecp2-/y mice on both control $1 \mathrm{IU} / \mathrm{g}$ and $10 \mathrm{lU} / \mathrm{g}$ VitD chow, compared with Mecp2+/y on control $1 \mathrm{lU} / \mathrm{g}$ chow. Dendritic complexity of Mecp2-/y mice on $50 \mathrm{IU} / \mathrm{g}$ VitD, however, is essentially indistinguishable from wild type (Mecp2+/y). E, Mecp2-/y mice on both control $1 \mathrm{IU} / \mathrm{g}$ and $10 \mathrm{IU} / \mathrm{g}$ VitD chow have reduced secondary and tertiary dendrite lengths, which are rescued in Mecp2-/y mice on 50 IU/g VitD. $\boldsymbol{F}$, The length of apical dendrites is also significantly lower in Mecp2-nulls on all chows, compared with wild-type mice. However, the length of basal dendrites of Mecp2-/y on $10 \mathrm{lU} / \mathrm{g}$ VitD and $50 \mathrm{lU} / \mathrm{g}$ VitD chow is rescued, and it is not significantly different from Mecp2+/y mice. G, Soma area of Layer II/III CPN is significantly reduced in Mecp2-/y cortex on both control chow and $10 \mathrm{IU} / \mathrm{g}$ VitD chow, relative to Mecp2+/y on control chow, but is rescued with $50 \mathrm{lU} / \mathrm{g}$ VitD. B, Two-way ANOVA, Bonferroni post hoc test. C-F, One-way ANOVA with Tukey's multiple comparison test; $* p<0.05, * * p<0.01$, $* * * p<0.001, \mathrm{NS}=$ not significant. $*$ Compared with Mecp2+/y. \# Compared with Mecp2-/y $1 \mathrm{IU} / \mathrm{g}$ VitD. B-F, N: Mecp2+/y IU = 21 neurons from three brains, Mecp2-/y $1 \mathrm{IU}=28 \mathrm{neu}-$ rons from four brains, $10 \mathrm{IU}=19$ neurons from three brains, $50 \mathrm{IU}=35$ neurons from five brains. $\mathbf{G}, \mathrm{N}$ : $M e c p 2+/ \mathrm{y} I \mathrm{IU}=228 \mathrm{neurons}$ from three brains, Mecp2-/y $1 \mathrm{IU}=263$ neurons from four brains, $10 \mathrm{IU}=193$ neurons from three brains, $50 \mathrm{IU}=204$ neurons from five brains. Error bar: \pm SEM.

We first investigated whether female Mecp2+/- also display aberrant NF- $\kappa$ B pathway activation. Overexpression of Irak1, encoding a signaling kinase and scaffold protein within the NF- $\kappa \mathrm{B}$ pathway, is highly prevalent in male Mecp2-/y mice, identified in a transcriptome study from CPN (Kishi et al., 2016), as well as in studies from other brain regions and different strains (Gabel et al., 2015). Overexpression of Irak1 leads to aberrant NF- $\kappa \mathrm{B}$ pathway activation and $\mathrm{NF}-\kappa \mathrm{B}$ 

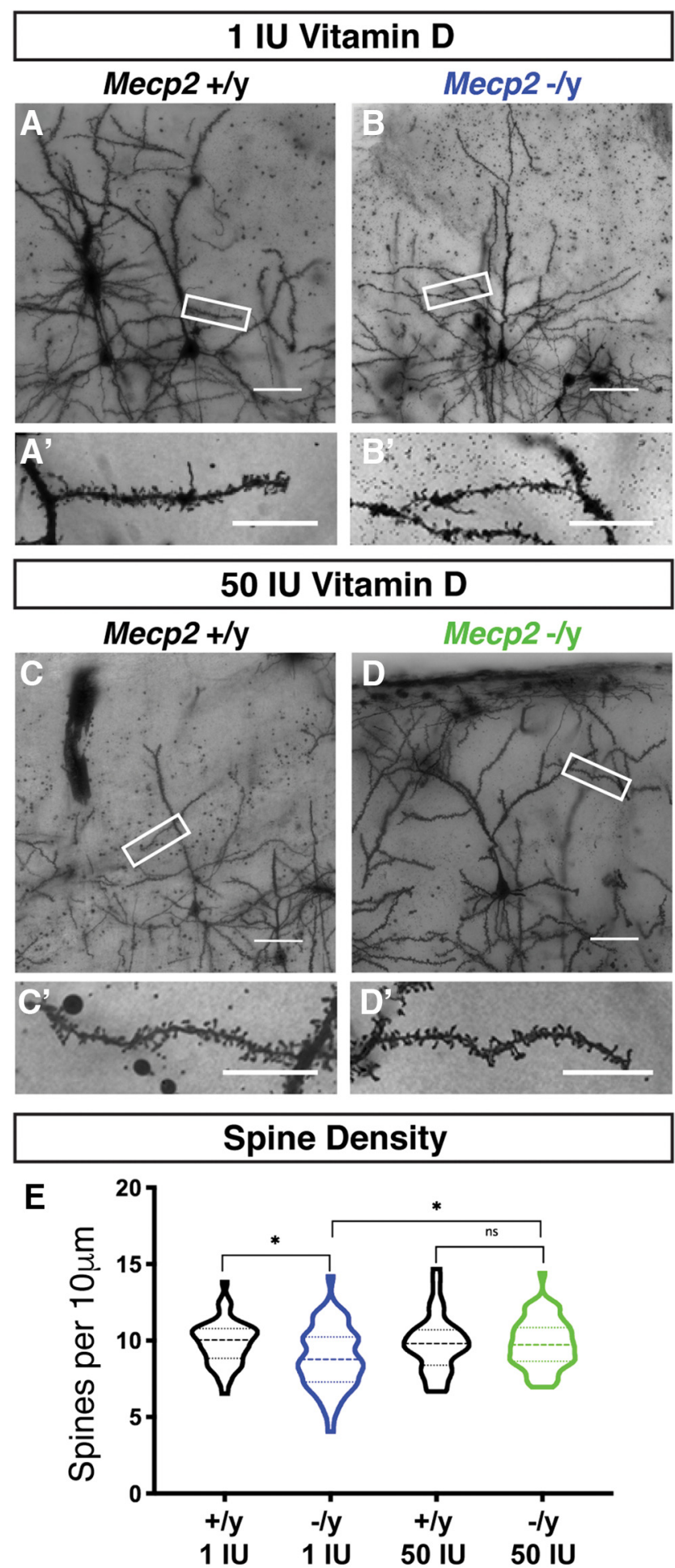

Figure 6. Vitamin D supplementation rescues reduced dendritic spine density in Mecp2-/y Layer II/III CPN. A-D, Representative images of apical dendrites of Layer II/III CPN in somatosensory cortex following Golgi staining. Boxes indicate areas displayed at higher magnification in $\boldsymbol{A}^{\prime} \boldsymbol{-} \boldsymbol{D}^{\prime}$. $\boldsymbol{E}$, Spine density is significantly decreased in Mecp2-null neurons compared with wild-type littermates. This decrease is rescued with $50 \mathrm{IU} / \mathrm{g}$ vitamin D supplementation; $* p<0.05$, one-way ANOVA with Tukey's multiple comparison test. $N=$ Mecp2+/y $1 \mathrm{IU}: 43$ dendrites from three brains, Mecp2-/y 1IU: 54 dendrites from three brains, pathway attenuation can rescue the reduced dendritic complexity of Mecp2-null neurons and extend the usually shortened lifespan of male Mecp2-null mice (Kishi et al., 2016). We find that Irak1 is significantly upregulated in the cortex of Mecp2+/- mice as well (Fig. 7A). Additionally, Camklld, a downstream target of the NF- $\kappa \mathrm{B}$ pathway, is upregulated in the cortex of Mecp2+/- mice when compared with their wild-type littermates (Fig. 7B), as previously reported in Mecp2-/y animals (Kishi et al., 2016). These results support the conclusion that aberrant NF- $\kappa \mathrm{B}$ pathway activation is also prevalent within the female Mecp2+/- neocortex and contributes to their neuronal phenotypes.

\section{Vitamin D supplementation partially rescues reduced CPN dendritic complexity in female heterozygous Mecp2+/- mice}

To investigate whether Mecp2+/- mice also display improvement of neuronal morphology phenotypes with vitamin D supplementation, Mecp2+/- and wild-type littermates $(M e c p 2+/+)$ were placed on custom chow at four weeks of age, as outlined for males. Vitamin D serum levels and dendritic complexity were analyzed at five months, an age at which cortical dendritic complexity and soma size phenotypes are already apparent (Rietveld et al., 2015) and Mecp2+/- mice consistently display motor impairments (Samaco et al., 2013). Unlike Mecp2null mice, Mecp2 +/ - females on control chow do not display significantly reduced levels of $25(\mathrm{OH}) \mathrm{D}$ under control conditions. However, $10 \mathrm{IU} / \mathrm{g}$ vitamin D dietary supplementation significantly increases $25(\mathrm{OH}) \mathrm{D}$ serum levels for both Mecp2+/+ and Mecp2+/- mice (Fig. 7C). Supplementation with both 10 and $50 \mathrm{lU} / \mathrm{g}$ vitamin D significantly increases Layer II/III CPN dendritic complexity in Mecp2+/- cortex, compared with Mecp2+/- on control chow, although it does not fully rescue to wild-type complexity (Fig. 7D,E). Similar to Mecp2-/y males, Mecp2+/females exhibit a reduced number of branch points and total dendritic length compared with their wild-type littermates. Although vitamin D supplementation does not fully rescue these phenotypes, there is a trend toward increased total dendritic length with vitamin $D$ supplementation, particularly $10 \mathrm{lU} / \mathrm{g}$ vitamin D (Fig. 7F,G). Mecp2+/- mice on $10 \mathrm{lU} / \mathrm{g}$ vitamin D demonstrate a significant increase in secondary dendrite length, relative to Mecp2 +/- on $1 \mathrm{IU} / \mathrm{g}$ vitamin D, with Mecp2+/- on both 10 and $50 \mathrm{lU} / \mathrm{g}$ vitamin D supplemented diets showing primary dendrite length that is not significantly different from wild type (Fig. $7 H$ ). Intriguingly, Mecp2+/- females on $10 \mathrm{lU} / \mathrm{g}$ vitamin D chow show a rescue in apical dendritic length (Fig. 7I). This differs from the Mecp2-null male mice, which demonstrated rescue of the length of their basal dendrites, but not of their apical dendrites. Additionally, supplementation of $10 \mathrm{lU} / \mathrm{g}$ vitamin $D$ appears to have the most beneficial effect by also rescuing the reduced soma size of Mecp2+/- Layer II/III CPN (Fig. 7J).

\section{continued}

Mecp2+/y 50 IU: 33 dendrites from three brains, Mecp2-/y 50 IU: 64 dendrites from four brains. Scale bar $=200 \mu \mathrm{m}(\boldsymbol{A}-\boldsymbol{D})$ and $5 \mu \mathrm{m}\left(\boldsymbol{A}^{\prime}-\boldsymbol{D}^{\prime}\right)$. ns $=$ not significant. Error bar \pm SEM. 
A

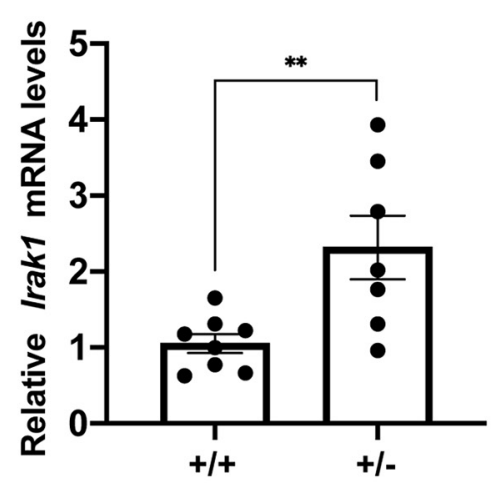

D
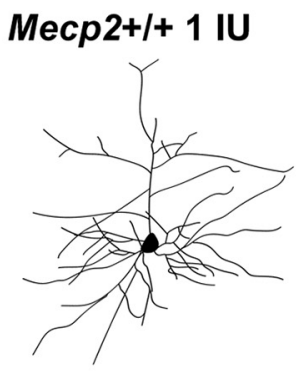

E

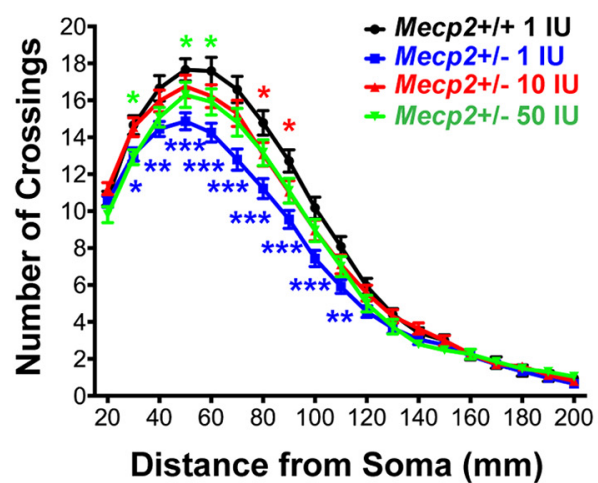

H

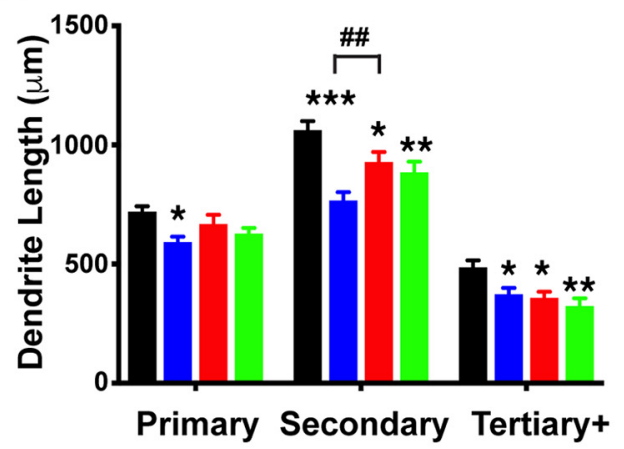

B

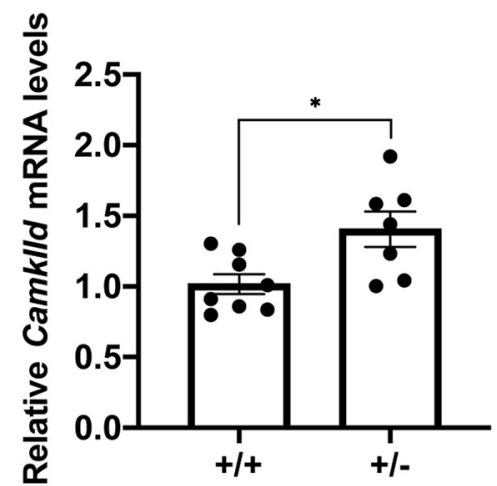

Mecp2+/- 1 IU

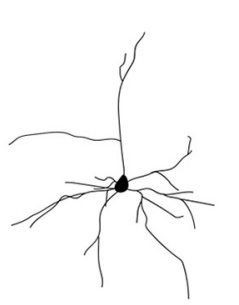

$\mathbf{F}$

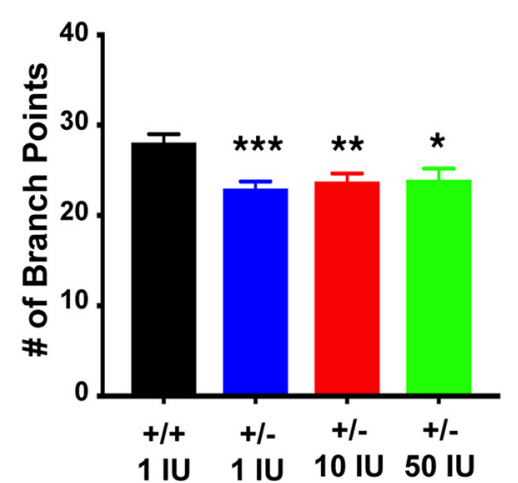

I

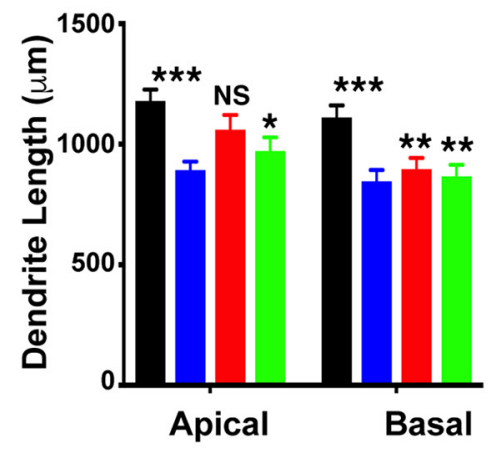

C

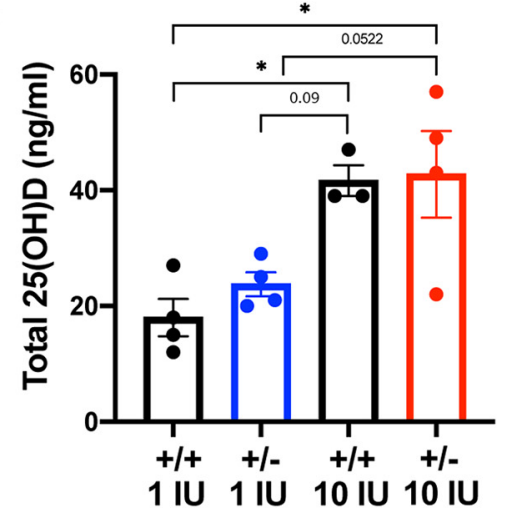

Mecp2+/- 10 IU

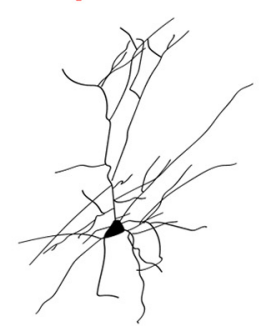

Mecp2+/= 50 IU

G

Figure 7. Mecp2+/- female cortex has increased Irak1 expression, and displays partial rescue of reduced dendritic complexity and soma size phenotypes with vitamin D (VitD) supplementation. A, Female Mecp2+/- cortex also displays upregulation of Irak1 expression at five months, as previously determined in male Mecp2-/y cortex at eight weeks (two-tailed $t$ test, $p=0.009 ; \mathrm{N}$ : Mecp2 $+/+$ $=8$, Mecp2 $+/-=7)$. B, Five-month-old Mecp2 $+/-$ mice show increased expression of the NF- $\kappa$ B downstream target Camklld (two-tailed $t$ test, $p=0.015 ; N$ : Mecp2 $+/+=8, M e c p 2+/-=7$ ). C, Mecp2+/- females on control chow (1 IU) do not display lower levels of VitD at five months of age; however, supplementing the diet of the mice with $10 \mathrm{lU} / \mathrm{g}$ VitD from four weeks of age significantly increases total serum levels of $25(\mathrm{OH}) \mathrm{D}$, independent of genotype. D. Representative traces of Layer II/III cortical CPNs. E. At five months of age, Mecp2+/- mice on both $10 \mathrm{lU} / \mathrm{g}$ and $50 \mathrm{lU} / \mathrm{g}$ VitD have increased dendritic complexity compared with Mecp2+/on control $1 \mathrm{lU} / \mathrm{g}$ chow, as measured by Golgi staining and Sholl analysis, although it is not fully rescued to wild-type $(\mathrm{Mecp} 2+/+)$ 
continued

levels. Asterisks denote significant difference for Mecp2+/- on $1 \mathrm{IU}$ (blue), $10 \mathrm{IU}$ (red), and $50 \mathrm{IU} / \mathrm{g}$ VitD (green) compared with Mecp2+/+ on control chow. $\boldsymbol{F}, \mathbf{G}$, Mecp2+/- on all VitD chows show reduced number of branch points $(\boldsymbol{F})$ and total dendritic length (G) compared with wild type, although there is a trend toward increased branch points and dendrite length with VitD supplementation. $\boldsymbol{H}, \boldsymbol{I}, M e c p 2+/-$ mice on $10 \mathrm{lU} / \mathrm{g}$ VitD demonstrate a significant increase in secondary dendrite length relative to control chow $(\boldsymbol{H})$, and apical dendritic length that is not significantly different from wild type (I). $\boldsymbol{J}$, Mecp2 $+/-$ mice on $10 \mathrm{IU} / \mathrm{g}$ VitD chow also show increased soma area, which is not significantly different from Mecp2+/+ mice on control chow. C, One-way ANOVA with Tukey's multiple comparisons test. $\boldsymbol{E}$, Two-way ANOVA with Bonferroni post hoc test. F-I, One-way ANOVA with Tukey's post hoc test. $\boldsymbol{C}, \mathrm{N}$ : Mecp2+/+ $1 \mathrm{IU}, M e c p 2+/-1 \mathrm{IU}$ and Mecp2+/- $10 \mathrm{IU}=4$ animals, Mecp2 $+/+10 \mathrm{IU}=3$ animals. $E-I, N: M e c p 2+/+1 \mathrm{IU}=46$ neurons from five brains, Mecp2 $+/-1 \mathrm{IU}=68$ neurons from six brains, $10 \mathrm{IU}=62$ neurons from six brains, $50 \mathrm{IU}=47$ neurons from five brains. $J, N=$ Mecp $2+/+1 \mathrm{IU}=192$ neurons from five brains, Mecp2 $+/-1 \mathrm{IU}=366$ neurons from six brains, $10 \mathrm{IU}=323$ neurons from six brains, $50 \mathrm{IU}=234$ neurons from five brains; $* p<0.05, * * p<0.01, * * * p<0.001$. NS = not significant. Error bar: \pm SEM.

Together, these results demonstrate that vitamin $\mathrm{D}$ supplementation in the 10 - to $50-\mathrm{IU} / \mathrm{g}$ range ameliorates neuronal size and complexity phenotypes in female heterozygous as well as male hemizygous null mice and further suggests that there might be sex-specific differences in optimal dose, so the treatment paradigm should be optimized independently for each sex. These results have implications more broadly regarding other potential pharmacologic routes to NF- $\kappa \mathrm{B}$ inhibition, perhaps contributing to RTT therapy.

\section{Discussion}

In this study, we tested the ability of vitamin $D$, a simple, cost-effective inhibitor of $\mathrm{NF}-\kappa \mathrm{B}$ signaling, to rescue the aberrant NF- $\kappa$ B pathway activation in Mecp2-mutant neurons and to improve specific RTT phenotypes. We identified a surprisingly efficacious, dose-dependent amelioration of both Layer II/III CPN dendritic complexity and soma size phenotypes, in addition to moderate improvements to overall health and longevity. Our multistage experiments show efficacy in both female Mecp2+/- mice that most closely model the human disease, and in male Mecp2-/y mice, which have been more widely used in earlier analyses due to their rapid progression. Our results have broader relevance for the potential of NF- $\kappa$ B pathway inhibition to contribute to therapeutic approaches for $\mathrm{RT}$, with a range of increasingly specific, controllable, and potentially targetable inhibitors of this pathway in existence or under development. That said, vitamin $\mathrm{D}$ provides more than simply a proof-of-concept, since it is already known to be safe, has no or little toxicity at the dosage ranges in question, and also directly addresses known vitamin $\mathrm{D}$ deficiency in $\mathrm{RTT}$ patients.

The NF- $\kappa$ B pathway regulates many cellular processes, including immune response, and Mecp2 knock-down has also been found to lead to enhanced NF- $\kappa \mathrm{B}$ signaling in myeloid lineage cells (O'Driscoll et al., 2013, 2015). NF$\kappa \mathrm{B}$ subunits are also expressed throughout the CNS, and there is an extensive literature implicating the NF- $\kappa$ B pathway in regulation of neural process development and structural plasticity, in addition to learning and memory (Gutierrez and Davies, 2011). Further, previous results demonstrate that genetic attenuation of this pathway in Mecp2-/y mice rescues RTT phenotypes (Kishi et al., 2016), and it has been shown that inhibition of the Gsk3b pathway improves neuronal morphology in Mecp2-null neurons by reducing NF- $\kappa \mathrm{B}$ signaling (Jorge-Torres et al.,
2018). Together, these results indicate that abnormal activation of NF- $\kappa$ B signaling contributes to the pathogenesis of Mecp2-null mice, and likely RTT. The broad neurologic phenotypes of RTT overlap with multiple other neurologic disorders, both neurodevelopmental (e.g., ASD, some forms of cerebral palsy, and epilepsy) and acquired (e.g., traumatic brain injury), raising interesting questions regarding converging underlying mechanisms and possible involvement of $\mathrm{NF}-\kappa \mathrm{B}$ signaling, either causal or potentially permissive for enhanced recovery. Thus, NF- $\kappa \mathrm{B}$ pathway inhibition might provide a novel therapeutic target not only for the devasting disorder RTT but also potentially to treat elements of neurologic disorders with overlapping pathology.

Previous studies have identified other compounds, such as rhIGF1, ketamine, and cannabidivarin, that appear to also significantly improve behavioral and morphologic phenotypes of Mecp2 mutant mice (Castro et al., 2014; Patrizi et al., 2016; Zamberletti et al., 2019). Further, genetic attenuation of the NF- $\kappa \mathrm{B}$ pathway (Kishi et al., 2016) is more effective at rescuing Mecp2-null lifespan than our early-symptomatic vitamin $D$ supplementation (Fig. 3), suggesting that either earlier onset of NF- $\kappa B$ pathway inhibition and/or other, more specific NF- $\kappa$ B inhibitors might be more efficacious. That said, our results reported here offer a straightforward, readily implementable, and immediately available option: vitamin $\mathrm{D}$, which is cost-effective and of easy access. For this reason, our work strongly motivates that vitamin $D$ supplementation be more thoroughly investigated as a simple, partial therapeutic avenue for RTT, likely in combination with other approaches.

Although the vitamin $D$ deficiency repeatedly observed in RTT patients has been largely attributed to poor nutrition and/or lack of exposure to sunlight, our results that Mecp2-null mice that are maintained in a controlled environment on chow considered to be vitamin $D$ sufficient also have reduced vitamin D serum levels (Fig. 1) suggest an underlying deficiency. One potential mechanism contributing to this vitamin $\mathrm{D}$ deficiency could be the disrupted cholesterol homeostasis reported in Mecp2-null mice (Buchovecky et al., 2013), since the primary natural source of vitamin $\mathrm{D}$ is dermal synthesis from cholesterol. The findings that heterozygous female mice maintained in the controlled environment do not display reduced vitamin D serum levels might indicate that their $\sim 50 \%$ mosaic of MeCP2 + cells is sufficient to maintain the synthesis of vitamin D. However, increased vitamin D still partially 
rescues the neuronal morphology phenotypes. Thus, it is interesting to speculate that $M e c p 2+/$ - maintained on a vitamin $\mathrm{D}$ deficient diet might likely have more severe phenotypes, perhaps more closely resembling the male Mecp2-/y mice.

In addition to the vitamin D receptor (VDR), which is mainly expressed in the nucleus of cells within the brain, protein disulfide isomerase family member 3 (PDIA3) is a known VDR localized in the cellular membrane (Nemere et al., 2004; Eyles et al., 2014). PDIA3 is associated with rapid nongenomic response to vitamin $\mathrm{D}$, although both receptors are thought to work in conjunction (Boyan et al., 2012; Chen et al., 2013a). While the expression of $V d r$ is very low in the brain compared with kidney and liver of rodents, Pdia3 displays greater abundance in brain than in other organs (Landel et al., 2018). We found no difference in Pdia3 expression in the cortex of either Mecp2 mutant male $(p=0.56)$ or female mice $(p=0.84)$, suggesting that they do not have a disruption in their ability to respond to vitamin D.

Our data suggest that vitamin D can act directly on cortical neurons to rescue their reduced dendritic complexity in vitro, with complementary work by us and by others indicating primarily direct action with regard to dendritic complexity. Mecp2 mutant cortical phenotypes result from both cell-autonomous and cell non-autonomous disruptions (Ribeiro and MacDonald, 2020). For example, reciprocal cross-transplantation studies demonstrate that Mecp2-/y CPN display reduced dendritic complexity even in the context of a wild-type cortex, but that soma size is dependent on the recipient cortical Mecp2 genotype (Kishi and Macklis, 2010). Further, in heterozygous females, dendritic complexity of Layer $\mathrm{V}$ cortical neurons correlates with MeCP2 cell-autonomous expression, while soma size is reduced even in wild-type neurons (Rietveld et al., 2015). In addition, the molecular pathways regulated by MeCP2 are tissue and cell-type specific (Samaco et al., 2009; Chao et al., 2010; Lioy et al., 2011; Derecki et al., 2012; Sugino et al., 2014), and loss of MeCP2 function in defined CNS circuits results in distinct RTT phenotypes (Alvarez-Saavedra et al., 2007; Fyffe et al., 2008; Adachi et al., 2009; Ward et al., 2011; Nguyen et al., 2013; Wither et al., 2013; He et al., 2014). NF- $\kappa$ B signaling is prevalent in glia, and the VDR is expressed by both neurons and astrocytes (Eyles et al., 2005). Thus, vitamin D might act on distinct cellular targets to differentially improve specific RTT phenotypes.

Interestingly, we also observe a sex difference in how Mecp2 mutant mice respond to our supplementation paradigm, though both sexes display increased circulating 25(OH)D after vitamin D dietary supplementation. Male Mecp2-null mice demonstrate CPN morphologic rescue when treated with $50 \mathrm{IU} / \mathrm{g}$ of vitamin $\mathrm{D}$ (Figs. 5,6 ) while heterozygous females respond better to $10 \mathrm{lU} / \mathrm{g}$ of vitamin D supplementation (Fig. 7). Furthermore, vitamin D supplementation rescues basal dendrite length in Mecp2-/y cortex (Fig. 5), and apical dendrite length in Mecp2+/females (Fig. 7). Different genes selectively control basal or apical dendritic maintenance (de Anda et al., 2012; Srivastava et al., 2012; Pathania et al., 2014; Cubelos et al., 2015; Rietveld et al., 2015). Therefore, it is tempting to speculate that the distinct treatment responses we see in males and females might be a result of different genes responding to Mecp2 mosaic expression in Mecp2+/mice and/or to non-cell autonomous effects regulating dendritic branching. Another consideration is the duration of the treatment: while mice of both sexes were placed on custom chow when weaned at P28, Mecp2-null male mice treatment lasted only four weeks, due to their shortened lifespan, while heterozygous female mice were on the custom diet for four months until reaching a typical symptomatic age.

In summary, we identify that dietary vitamin $D$ supplementation, within a widely acceptable and nontoxic dosage range, rescues aberrant NF- $\kappa$ B pathway activation and partially ameliorates downstream neuropathological effects of NF- $\kappa \mathrm{B}$ signaling in Mecp2 mutant mice. These results further solidify the NF- $\kappa \mathrm{B}$ pathway as a potential novel therapeutic target for RTT. We demonstrate that vitamin D inhibits this pathway in Mecp2 knock-down neurons in vitro, ameliorates reduced neocortical dendritic morphology and soma size phenotypes in a dose-dependent manner in vivo in both male and female RTT model mice, and modestly improves the reduced lifespan of male Mecp2-null mice. While it is known that neuronal morphologic rescue can lead to behavioral improvements of Mecp2-null mice (Bu et al., 2017; Chin et al., 2019), it will be important for future studies to assess both complex mouse behavior and electrophysiological properties of Mecp2-null neurons in mice with vitamin D supplementation, to further investigate the breadth of therapeutic potential of vitamin D supplementation and the specific phenotypes that are or are not improved. Together, our results both provide new insight into the fundamental neurobiology of RTT, and motivate consideration of NF$\kappa \mathrm{B}$ pathway inhibition, including via vitamin $\mathrm{D}$ dietary supplementation, as a potential partial therapeutic intervention for RTT.

\section{References}

Adachi M, Autry AE, Covington HE 3rd, Monteggia LM (2009) MeCP2-mediated transcription repression in the basolateral amygdala may underlie heightened anxiety in a mouse model of Rett syndrome. J Neurosci 29:4218-4227.

Alvarez-Saavedra M, Sáez MA, Kang D, Zoghbi HY, Young JI (2007) Cell-specific expression of wild-type MeCP2 in mouse models of Rett syndrome yields insight about pathogenesis. Hum Mol Genet 16:2315-2325.

Amir RE, Van den Veyver IB, Wan M, Tran CQ, Francke U, Zoghbi HY (1999) Rett syndrome is caused by mutations in X-linked MECP2, encoding methyl-CpG-binding protein 2. Nat Genet 23:185-188.

Armstrong D, Dunn JK, Antalffy B, Trivedi R (1995) Selective dendritic alterations in the cortex of Rett syndrome. J Neuropathol Exp Neurol 54:195-201.

Belichenko PV, Oldfors A, Hagberg B, Dahlström A (1994) Rett syndrome: 3-D confocal microscopy of cortical pyramidal dendrites and afferents. Neuroreport 5:1509-1513.

Belichenko NP, Belichenko PV, Mobley WC (2009) Evidence for both neuronal cell autonomous and nonautonomous effects of methylCpG-binding protein 2 in the cerebral cortex of female mice with Mecp2 mutation. Neurobiol Dis 34:71-77. 
Boyan BD, Chen J, Schwartz Z (2012) Mechanism of Pdia3-dependent $1 \alpha, 25$-dihydroxy vitamin D3 signaling in musculoskeletal cells. Steroids 77:892-896.

Bu Q, Wang A, Hamzah H, Waldman A, Jiang K, Dong Q, Li R, Kim J, Turner D, Chang Q (2017) CREB signaling is involved in Rett syndrome pathogenesis. J Neurosci 37:3671-3685.

Buchovecky CM, Turley SD, Brown HM, Kyle SM, McDonald JG, Liu B, Pieper AA, Huang W, Katz DM, Russell DW, Shendure J, Justice MJ (2013) A suppressor screen in Mecp2 mutant mice implicates cholesterol metabolism in Rett syndrome. Nat Genet 45:10131020.

Burgess A, Vigneron S, Brioudes E, Labbé JC, Lorca T, Castro A (2010) Loss of human Greatwall results in G2 arrest and multiple mitotic defects due to deregulation of the cyclin B-Cdc2/PP2A balance. Proc Natl Acad Sci USA 107:12564-12569.

Cannell JJ (2013) Autism, will vitamin D treat core symptoms? Med Hypotheses 81:195-198.

Castro J, Garcia RI, Kwok S, Banerjee A, Petravicz J, Woodson J, Mellios N, Tropea D, Sur M (2014) Functional recovery with recombinant human IGF1 treatment in a mouse model of Rett Syndrome. Proc Natl Acad Sci USA 111:9941-9946.

Chahrour M, Zoghbi HY (2007) The story of Rett syndrome: from clinic to neurobiology. Neuron 56:422-437.

Chao HT, Chen H, Samaco RC, Xue M, Chahrour M, Yoo J, Neul JL, Gong S, Lu HC, Heintz N, Ekker M, Rubenstein JL, Noebels JL, Rosenmund C, Zoghbi HY (2010) Dysfunction in GABA signalling mediates autism-like stereotypies and Rett syndrome phenotypes. Nature 468:263-269.

Chen J, Doroudi M, Cheung J, Grozier AL, Schwartz Z, Boyan BD (2013a) Plasma membrane Pdia3 and VDR interact to elicit rapid responses to $1 \alpha, 25(\mathrm{OH})(2) \mathrm{D}(3)$. Cell Signal 25:2362-2373.

Chen Y, Zhang J, Ge X, Du J, Deb DK, Li YC (2013b) Vitamin D receptor inhibits nuclear factor $\kappa \mathrm{B}$ activation by interacting with $\mathrm{I}_{\kappa} \mathrm{B}$ kinase $\beta$ protein. J Biol Chem 288:19450-19458.

Chin EWM, Lim WM, Ma D, Rosales FJ, Goh ELK (2019) Choline rescues behavioural deficits in a mouse model of Rett syndrome by modulating neuronal plasticity. Mol Neurobiol 56:3882-3896.

Cubelos B, Briz CG, Esteban-Ortega GM, Nieto M (2015) Cux1 and Cux2 selectively target basal and apical dendritic compartments of layer II-III cortical neurons. Dev Neurobiol 75:163-172.

Cui X, Gooch H, Petty A, McGrath JJ, Eyles D (2017) Vitamin D and the brain: genomic and non-genomic actions. Mol Cell Endocrinol 453:131-143.

Davis RL, Syapin PJ (2004) Ethanol increases nuclear factor-kappa B activity in human astroglial cells. Neurosci Lett 371:128-132.

de Anda FC, Rosario AL, Durak O, Tran T, Gräff J, Meletis K, Rei D, Soda T, Madabhushi R, Ginty DD, Kolodkin AL, Tsai LH (2012) Autism spectrum disorder susceptibility gene TAOK2 affects basal dendrite formation in the neocortex. Nat Neurosci 15:1022-1031.

Derecki NC, Cronk JC, Lu Z, Xu E, Abbott SB, Guyenet PG, Kipnis J (2012) Wild-type microglia arrest pathology in a mouse model of Rett syndrome. Nature 484:105-109.

Du L, Zhao G, Duan Z, Li F (2017) Behavioral improvements in a valproic acid rat model of autism following vitamin $D$ supplementation. Psychiatry Res 253:28-32.

Egaas B, Courchesne E, Saitoh O (1995) Reduced size of corpus callosum in autism. Arch Neurol 52:794-801.

Eyles DW, Smith S, Kinobe R, Hewison M, McGrath JJ (2005) Distribution of the vitamin $\mathrm{D}$ receptor and 1 alpha-hydroxylase in human brain. J Chem Neuroanat 29:21-30.

Eyles DW, Burne TH, McGrath JJ (2013) Vitamin D, effects on brain development, adult brain function and the links between low levels of vitamin $D$ and neuropsychiatric disease. Front Neuroendocrinol 34:47-64.

Eyles DW, Liu PY, Josh P, Cui X (2014) Intracellular distribution of the vitamin $D$ receptor in the brain: comparison with classic target tissues and redistribution with development. Neuroscience 268:1-9.

Fame RM, MacDonald JL, Macklis JD (2011) Development, specification, and diversity of callosal projection neurons. Trends Neurosci 34:41-50.
Fernell E, Bejerot S, Westerlund J, Miniscalco C, Simila H, Eyles D, Gillberg C, Humble MB (2015) Autism spectrum disorder and low vitamin D at birth: a sibling control study. Mol Autism 6:3.

Frazier TW, Hardan AY (2009) A meta-analysis of the corpus callosum in autism. Biol Psychiatry 66:935-941.

Fukuda T, Itoh M, Ichikawa T, Washiyama K, Goto Y (2005) Delayed maturation of neuronal architecture and synaptogenesis in cerebral cortex of Mecp2-deficient mice. J Neuropathol Exp Neurol 64:537-544.

Fyffe SL, Neul JL, Samaco RC, Chao HT, Ben-Shachar S, Moretti P, McGill BE, Goulding EH, Sullivan E, Tecott LH, Zoghbi HY (2008) Deletion of Mecp2 in Sim1-expressing neurons reveals a critical role for MeCP2 in feeding behavior, aggression, and the response to stress. Neuron 59:947-958.

Gabel HW, Kinde B, Stroud H, Gilbert CS, Harmin DA, Kastan NR, Hemberg M, Ebert DH, Greenberg ME (2015) Disruption of DNAmethylation-dependent long gene repression in Rett syndrome. Nature 522:89-93.

Giacometti E, Luikenhuis S, Beard C, Jaenisch R (2007) Partial rescue of MeCP2 deficiency by postnatal activation of MeCP2. Proc Natl Acad Sci USA 104:1931-1936.

Gianforcaro A, Hamadeh MJ (2012) Dietary vitamin D3 supplementation at $10 x$ the adequate intake improves functional capacity in the G93A transgenic mouse model of ALS, a pilot study. CNS Neurosci Ther 18:547-557.

Gianforcaro A, Solomon JA, Hamadeh MJ (2013) Vitamin D(3) at 50x Al attenuates the decline in paw grip endurance, but not disease outcomes, in the G93A mouse model of ALS, and is toxic in females. PLoS One 8:e30243.

Gutierrez H, Davies AM (2011) Regulation of neural process growth, elaboration and structural plasticity by NF-kappaB. Trends Neurosci 34:316-325.

Guy J, Hendrich B, Holmes M, Martin JE, Bird A (2001) A mouse Mecp2-null mutation causes neurological symptoms that mimic Rett syndrome. Nat Genet 27:322-326.

Guy J, Gan J, Selfridge J, Cobb S, Bird A (2007) Reversal of neurological defects in a mouse model of Rett syndrome. Science 315:1143-1147.

Hardan AY, Pabalan M, Gupta N, Bansal R, Melhem NM, Fedorov S, Keshavan MS, Minshew NJ (2009) Corpus callosum volume in children with autism. Psychiatry Res 174:57-61.

He LJ, Liu N, Cheng TL, Chen XJ, Li YD, Shu YS, Qiu ZL, Zhang XH (2014) Conditional deletion of Mecp2 in parvalbumin-expressing GABAergic cells results in the absence of critical period plasticity. Nat Commun 5:5036.

Herbert MR, Kenet T (2007) Brain abnormalities in language disorders and in autism. Pediatr Clin North Am 54:563-583, vii.

Hollo A, Clemens Z, Lakatos P (2014) Epilepsy and vitamin D. Int J Neurosci 124:387-393.

Hynd GW, Semrud-Clikeman M, Lorys AR, Novey ES, Eliopulos D, Lyytinen H (1991) Corpus callosum morphology in attention deficit-hyperactivity disorder: morphometric analysis of MRI. J Learn Disabil 24:141-146.

Innocenti GM, Ansermet F, Parnas J (2003) Schizophrenia, neurodevelopment and corpus callosum. Mol Psychiatry 8:261-274.

Jia F, Wang B, Shan L, Xu Z, Staal WG, Du L (2015) Core symptoms of autism improved after vitamin $D$ supplementation. Pediatrics 135:e196-e198.

Jorge-Torres OC, Szczesna K, Roa L, Casal C, GonzalezSomermeyer L, Soler M, Velasco CD, Martínez-San Segundo P, Petazzi P, Sáez MA, Delgado-Morales R, Fourcade S, Pujol A, Huertas D, Llobet A, Guil S, Esteller M (2018) Inhibition of Gsk3b reduces Nfkb1 signaling and rescues synaptic activity to improve the Rett syndrome phenotype in Mecp2-knockout mice. Cell Rep 23:1665-1677.

Katz DM, Berger-Sweeney JE, Eubanks JH, Justice MJ, Neul JL, Pozzo-Miller L, Blue ME, Christian D, Crawley JN, Giustetto M, Guy J, Howell CJ, Kron M, Nelson SB, Samaco RC, Schaevitz LR, St Hillaire-Clarke C, Young JL, Zoghbi HY, Mamounas LA (2012) 
Preclinical research in Rett syndrome: setting the foundation for translational success. Dis Model Mech 5:733-745.

Kishi N, Macklis JD (2004) MECP2 is progressively expressed in post-migratory neurons and is involved in neuronal maturation rather than cell fate decisions. Mol Cell Neurosci 27:306-321.

Kishi N, Macklis JD (2010) MeCP2 functions largely cell-autonomously, but also non-cell-autonomously, in neuronal maturation and dendritic arborization of cortical pyramidal neurons. Exp Neurol 222:51-58.

Kishi N, MacDonald JL, Ye J, Molyneaux BJ, Azim E, Macklis JD (2016) Reduction of aberrant NF- $\kappa$ B signalling ameliorates Rett syndrome phenotypes in Mecp2-null mice. Nat Commun 7:10520.

Landel V, Stephan D, Cui X, Eyles D, Feron F (2018) Differential expression of vitamin D-associated enzymes and receptors in brain cell subtypes. J Steroid Biochem Mol Biol 177:129-134.

Latimer CS, Brewer LD, Searcy JL, Chen KC, Popović J, Kraner SD, Thibault O, Blalock EM, Landfield PW, Porter NM (2014) Vitamin D prevents cognitive decline and enhances hippocampal synaptic function in aging rats. Proc Natl Acad Sci USA 111:E4359-E4366.

Lioy DT, Garg SK, Monaghan CE, Raber J, Foust KD, Kaspar BK, Hirrlinger PG, Kirchhoff F, Bissonnette JM, Ballas N, Mandel G (2011) A role for glia in the progression of Rett's syndrome. Nature 475:497-500.

Lippai D, Bala S, Csak T, Kurt-Jones EA, Szabo G (2013) Chronic alcohol-induced microRNA-155 contributes to neuroinflammation in a TLR4-dependent manner in mice. PLoS One 8:e70945.

Luikenhuis S, Giacometti E, Beard CF, Jaenisch R (2004) Expression of MeCP2 in postmitotic neurons rescues Rett syndrome in mice. Proc Natl Acad Sci USA 101:6033-6038.

Lundqvist J, Yde CW, Lykkesfeldt AE (2014) 1 $\alpha$,25-dihydroxyvitamin D3 inhibits cell growth and $\mathrm{NF} \kappa \mathrm{B}$ signaling in tamoxifen-resistant breast cancer cells. Steroids 85:30-35.

Manzini MC, Xiong L, Shaheen R, Tambunan DE, Di Costanzo S, Mitisalis V, Tischfield DJ, Cinquino A, Ghaziuddin M, Christian M, Jiang Q, Laurent S, Nanjiani ZA, Rasheed S, Hill RS, Lizarraga SB, Gleason D, Sabbagh D, Salih MA, Alkuraya FS, et al. (2014) CC2D1A regulates human intellectual and social function as well as NF- $\kappa$ B signaling homeostasis. Cell Rep 8:647-655.

Mayne PE, Burne THJ (2019) Vitamin D in synaptic plasticity, cognitive function, and neuropsychiatric illness. Trends Neurosci 42:293-306.

McCloy RA, Rogers S, Caldon CE, Lorca T, Castro A, Burgess A (2014) Partial inhibition of Cdk1 in G 2 phase overrides the SAC and decouples mitotic events. Cell Cycle 13:1400-1412.

McGraw CM, Samaco RC, Zoghbi HY (2011) Adult neural function requires MeCP2. Science 333:186.

Mochida GH, Mahajnah M, Hill AD, Basel-Vanagaite L, Gleason D, Hill RS, Bodell A, Crosier M, Straussberg R, Walsh CA (2009) A truncating mutation of TRAPPC9 is associated with autosomal-recessive intellectual disability and postnatal microcephaly. Am J Hum Genet 85:897-902.

Motil KJ, Barrish JO, Lane J, Geerts SP, Annese F, McNair L, Percy AK, Skinner SA, Neul JL, Glaze DG (2011) Vitamin D deficiency is prevalent in girls and women with Rett syndrome. J Pediatr Gastroenterol Nutr 53:569-574.

Mukaetova-Ladinska EB, Arnold H, Jaros E, Perry R, Perry E (2004) Depletion of MAP2 expression and laminar cytoarchitectonic changes in dorsolateral prefrontal cortex in adult autistic individuals. Neuropathol Appl Neurobiol 30:615-623.

Nemere I, Farach-Carson MC, Rohe B, Sterling TM, Norman AW, Boyan BD, Safford SE (2004) Ribozyme knockdown functionally links a 1,25(OH)2D3 membrane binding protein (1,25D3-MARRS) and phosphate uptake in intestinal cells. Proc Natl Acad Sci USA 101:7392-7397.

Nguyen MV, Du F, Felice CA, Shan X, Nigam A, Mandel G, Robinson JK, Ballas N (2012) MeCP2 is critical for maintaining mature neuronal networks and global brain anatomy during late stages of postnatal brain development and in the mature adult brain. $\mathrm{J}$ Neurosci 32:10021-10034.
Nguyen MV, Felice CA, Du F, Covey MV, Robinson JK, Mandel G, Ballas N (2013) Oligodendrocyte lineage cells contribute unique features to Rett syndrome neuropathology. J Neurosci 33:1876418774.

O'Driscoll CM, Kaufmann WE, Bressler JP (2013) MeCP2 deficiency enhances glutamate release through NF- $\kappa$ B signaling in myeloid derived cells. J Neuroimmunol 265:61-67.

O'Driscoll CM, Lima MP, Kaufmann WE, Bressler JP (2015) Methyl CpG binding protein 2 deficiency enhances expression of inflammatory cytokines by sustaining NF- $\kappa$ B signaling in myeloid derived cells. J Neuroimmunol 283:23-29.

Okabe T, Chavan R, Fonseca Costa SS, Brenna A, Ripperger JA, Albrecht U (2016) REV-ERB $\alpha$ influences the stability and nuclear localization of the glucocorticoid receptor. J Cell Sci 129:41434154.

Pathania M, Davenport EC, Muir J, Sheehan DF, López-Doménech G, Kittler JT (2014) The autism and schizophrenia associated gene CYFIP1 is critical for the maintenance of dendritic complexity and the stabilization of mature spines. Transl Psychiatry 4:e374.

Patrick RP, Ames BN (2014) Vitamin D hormone regulates serotonin synthesis. Part 1: relevance for autism. FASEB J 28:2398-2413.

Patrizi A, Picard N, Simon AJ, Gunner G, Centofante E, Andrews NA, Fagiolini M (2016) Chronic administration of the N-methyl-D-aspartate receptor antagonist ketamine improves Rett syndrome phenotype. Biol Psychiatry 79:755-764.

Philippe O, Rio M, Carioux A, Plaza JM, Guigue P, Molinari F, Boddaert N, Bole-Feysot C, Nitschke P, Smahi A, Munnich A, Colleaux $L$ (2009) Combination of linkage mapping and microarray-expression analysis identifies NF- $\kappa$ B signaling defect as a cause of autosomal-recessive mental retardation. Am $\mathrm{J}$ Hum Genet 85:903-908.

Piven J, Bailey J, Ranson BJ, Arndt S (1997) An MRI study of the corpus callosum in autism. Am J Psychiatry 154:1051-1056.

Ribeiro MC, MacDonald JL (2020) Sex differences in Mecp2-mutant Rett syndrome model mice and the impact of cellular mosaicism in phenotype development. Brain Res 1729:146644.

Rietveld L, Stuss DP, McPhee D, Delaney KR (2015) Genotype-specific effects of Mecp2 loss-of-function on morphology of layer $\mathrm{V}$ pyramidal neurons in heterozygous female Rett syndrome model mice. Front Cell Neurosci 9:145.

Risher WC, Ustunkaya T, Singh Alvarado J, Eroglu C (2014) Rapid Golgi analysis method for efficient and unbiased classification of dendritic spines. PLoS One 9:e107591.

Roessner V, Banaschewski T, Uebel H, Becker A, Rothenberger A (2004) Neuronal network models of ADHD - lateralization with respect to interhemispheric connectivity reconsidered. Eur Child Adolesc Psychiatry 13 [Suppl 1]:171-I79.

Samaco RC, Mandel-Brehm C, Chao HT, Ward CS, Fyffe-Maricich SL, Ren J, Hyland K, Thaller C, Maricich SM, Humphreys P, Greer JJ, Percy A, Glaze DG, Zoghbi HY, Neul JL (2009) Loss of MeCP2 in aminergic neurons causes cell-autonomous defects in neurotransmitter synthesis and specific behavioral abnormalities. Proc Natl Acad Sci USA 106:21966-21971.

Samaco RC, McGraw CM, Ward CS, Sun Y, Neul JL, Zoghbi HY (2013) Female Mecp2(+/-) mice display robust behavioral deficits on two different genetic backgrounds providing a framework for pre-clinical studies. Hum Mol Genet 22:96-109.

Sarajlija A, Djuric M, Tepavcevic DK, Grkovic S, Djordjevic M (2013) Vitamin D deficiency in Serbian patients with Rett syndrome. J Clin Endocrinol Metab 98:E1972-E1978.

Seidman LJ, Valera EM, Makris N (2005) Structural brain imaging of attention-deficit/hyperactivity disorder. Biol Psychiatry 57:12631272.

Sholl DA (1953) Dendritic organization in the neurons of the visual and motor cortices of the cat. J Anat 87:387-406.

Spach KM, Hayes CE (2005) Vitamin D3 confers protection from autoimmune encephalomyelitis only in female mice. J Immunol 175:4119-4126.

Srivastava DP, Woolfrey KM, Jones KA, Anderson CT, Smith KR, Russell TA, Lee H, Yasvoina MV, Wokosin DL, Ozdinler PH, 
Shepherd GM, Penzes P (2012) An autism-associated variant of Epac2 reveals a role for Ras/Epac2 signaling in controlling basal dendrite maintenance in mice. PLoS Biol 10:e1001350.

Stio M, Martinesi M, Bruni S, Treves C, Mathieu C, Verstuyf A, d'Albasio G, Bagnoli S, Bonanomi AG (2007) The vitamin D analogue TX 527 blocks NF-kappaB activation in peripheral blood mononuclear cells of patients with Crohn's disease. J Steroid Biochem Mol Biol 103:51-60.

Sugino K, Hempel CM, Okaty BW, Arnson HA, Kato S, Dani VS, Nelson SB (2014) Cell-type-specific repression by methyl-CpGbinding protein 2 is biased toward long genes. J Neurosci 34:12877-12883.

Swayze VW 2nd, Andreasen NC, Ehrhardt JC, Yuh WT, Alliger RJ, Cohen GA (1990) Developmental abnormalities of the corpus callosum in schizophrenia. Arch Neurol 47:805-808.

Tibbo P, Nopoulos P, Arndt S, Andreasen NC (1998) Corpus callosum shape and size in male patients with schizophrenia. Biol Psychiatry 44:405-412.

Vetreno RP, Crews FT (2018) Adolescent binge ethanol-induced loss of basal forebrain cholinergic neurons and neuroimmune activation are prevented by exercise and indomethacin. PLoS One 13: e0204500.

Vogel Ciernia A, Pride MC, Durbin-Johnson B, Noronha A, Chang A, Yasui DH, Crawley JN, LaSalle JM (2017) Early motor phenotype detection in a female mouse model of Rett syndrome is improved by cross-fostering. Hum Mol Genet 26:1839-1854.
Vuillermot S, Luan W, Meyer U, Eyles D (2017) Vitamin D treatment during pregnancy prevents autism-related phenotypes in a mouse model of maternal immune activation. Mol Autism 8:9.

Ward CS, Arvide EM, Huang TW, Yoo J, Noebels JL, Neul JL (2011) MeCP2 is critical within HoxB1-derived tissues of mice for normal lifespan. J Neurosci 31:10359-10370.

Wither RG, Lang M, Zhang L, Eubanks JH (2013) Regional MeCP2 expression levels in the female MeCP2-deficient mouse brain correlate with specific behavioral impairments. Exp Neurol 239:49-59.

Wolf RC, Höse A, Frasch K, Walter H, Vasic N (2008) Volumetric abnormalities associated with cognitive deficits in patients with schizophrenia. Eur Psychiatry 23:541-548.

Wood L, Gray NW, Zhou Z, Greenberg ME, Shepherd GM (2009) Synaptic circuit abnormalities of motor-frontal layer $2 / 3$ pyramidal neurons in an RNA interference model of methyl-CpG-binding protein 2 deficiency. J Neurosci 29:12440-12448.

Zamberletti E, Gabaglio M, Piscitelli F, Brodie JS, Woolley-Roberts M, Barbiero I, Tramarin M, Binelli G, Landsberger N, KilstrupNielsen C, Rubino T, Di Marzo V, Parolaro D (2019) Cannabidivarin completely rescues cognitive deficits and delays neurological and motor defects in male Mecp2 mutant mice. J Psychopharmacol 33:894-907.

Zhou Z, Hong EJ, Cohen S, Zhao WN, Ho HY, Schmidt L, Chen WG, Lin Y, Savner E, Griffith EC, Hu L, Steen JA, Weitz CJ, Greenberg ME (2006) Brain-specific phosphorylation of MeCP2 regulates activity-dependent Bdnf transcription, dendritic growth, and spine maturation. Neuron 52:255-269. 